\title{
An Assessment of the Effects of the 2002 Food Crisis on Children's Health in Malawi
}

\author{
Renate Hartwig \\ International Institute of Social Studies, Erasmus University Rotterdam \\ Michael Grimm* \\ International Institute of Social Studies, Erasmus University Rotterdam
}

Forthcoming in Journal of African Economies [doi: 10.1093/jae/ejr028]

(June 2011)

\begin{abstract}
The food crisis encountered in 2002 in Malawi was arguably one of the worst in the recent history of the country. The World Food Programme estimated that between 2.1 to 3.2 million people were threatened by starvation. Despite this assumed severity, not much research on the actual consequences of the crisis has been carried out so far. In order to fill this gap, this paper aims to identify the effects of the 2002 food crisis on the health status of the very young children exposed to it. Given the lack of longitudinal data and data collected during the crisis, assessing the potential impact of the 2002 events and the emergency aid that followed is challenging. We rely on representative data collected before and after the crisis and various methods from the impact evaluation literature to create a counterfactual in order to assess the implications of the crisis. Our analysis indicates that the net impact of the crisis was surprisingly low. Under-five excess mortality must have been below the 10,000 crisis-induced deaths suggested by some NGOs. Moreover, we also do not find any general and lasting loss in weight or height of children below the age of five. Nevertheless, if we disaggregate our sample population further by age and gender, we do find some nutritional impacts, both positive and negative. The positive effects identified seem to be the result of the combined influence of selective mortality and effective aid and policy interventions responding to the crisis.
\end{abstract}

JEL Classification: I12, J13.

Keywords: Child Mortality, Malnutrition, Food Crisis, Malawi.

\footnotetext{
${ }^{1}$ We are grateful for very useful comments by two anonymous referees, the editor, Marcel Fafchamps, as well as Arjun Bedi and Robert Sparrow and participants at the CSAE conference 2010 in Oxford. All remaining errors are of course our own.

* Corresponding author: Michael Grimm, International Institute of Social Studies, Erasmus University Rotterdam, Kortenaerkade 12, 2518 AX The Hague, The Netherlands, Phone: +31-70-4260694, Fax: +31-704260799, E-mail: grimm@iss.nl.
} 
Malawi is frequently exposed to food shortages due to crop failure. ${ }^{2}$ However, the situation faced in 2002 was reportedly one of the worst in the recent history of the country, putting about one quarter of the population on the verge of starvation. Due to a lack of reliable data, estimates on the related excess mortality vary significantly. The range runs from 300 to $500^{3}$ cases, up to estimates of 10,000 to 15,000 crisis-related deaths (Devereux, 2000b; Taifour, 2002). Even though experts consider this latter estimate to be exaggerated, ${ }^{4}$ the WHO (2002) also claims that child mortality rates doubled in some districts during the crisis year, which would have led to at least 9,000 additional child deaths alone. ${ }^{5}$ Apart from these rather vague mortality figures, there has, so far, been no further rigorous, quantitative assessment of the implications of this crisis. ${ }^{6}$

Taking a step forward on this, and bearing in mind the potential 100 percent increase in child mortality in some districts, the present paper will take a closer look at the health effects of this event. More specifically, we aim to identify the impact of food deprivation on the health status of children aged five and below. Due to data constraints, our assessment of the health implications is limited to changes in children's anthropometry. However, we will also aim to verify the suggested mortality estimates. Moreover, we concentrate our analysis on an estimation of the net effects of the crisis: that is the effects of the crisis in conjunction with the policy interventions that were implemented in response, such as the free distribution of food and agricultural inputs.

There is ample evidence that food deprivation and a lack of nutrients have significant negative impacts on child health. Particularly the first 36 months of life have been found to be crucial for later development. Hence, one would expect that, with its reported magnitude, the 2002 food crisis led to a significant deterioration of the health of children exposed to the food shortage. However, when considering an assessment of the average impact of the crisis, two more issues have to be taken into account: (i) selective attrition, and (ii) potential catch-up. With respect to the first, it has been argued that in situations of severe food crises with high rates of excess mortality, survivors constitute a highly selective group, which may be resilient and not exhibit symptoms of negative effects. ${ }^{7}$ Thus, if selection is high, we might not be able to identify differences in observed health outcomes between affected and non-affected groups.

With respect to the second issue, conditional on survival, a number of studies indicate that, particularly with respect to child growth and cognitive development, catch-up can be observed in the aftermaths of negative events if sufficient and adequate rehabilitative

\footnotetext{
${ }^{2}$ From 1970 to 2007 for example, the country experienced about 40 weather related disasters causing harvest losses (Roshni, 2007).

${ }^{3}$ Even assuming the lowest estimates, the 2002 crisis would have been more severe than the Nyasaland famine of 1949 with estimated deaths of 'only' 200.

${ }^{4}$ According to expert opinion, the most realistic estimate ranges from 1,000 to 3,000 excess deaths (Devereux, 2000b).

${ }^{5}$ More precisely, the WHO estimated child mortality rates in some of the districts most severely hit at ca. $3.9 / 10,000$ per day (i.e. a doubling of the usual mortality rates of 2/10.000 per day) lasting at least from April until September 2002. Based on the census data, that would imply an excess mortality of 156 per day or about 9,000 over two months (WHO, 2002).

${ }^{6}$ Most previous studies have explored the causes of the food shortfall (see, for example, Devereux, 2002a and 2002b; Stevens et al., 2002; and Kydd et al., 2002), but only very few researchers (e.g. Dorward and Kydd, 2004) touched on the effects of the policy interventions undertaken at the time.

${ }^{7}$ See e.g. Gorgens et al. (2007).
} 
measures are taken. ${ }^{8}$ Even though there is no clear indication of the timing of potential catchup development, studies which have identified a catching-up, particularly concerning child growth, have commonly focused on long-term effects. In contrast, our analysis is more concerned with the short-term implications, thus catch-up might not be an issue.

In addition to selectivity and catch-up, our analysis is further complicated by a lack of data. Ideally, this type of analysis should be based on longitudinal data that would allow tracking children before, during and after the crisis. In the absence of this type of data, we have to rely on cross-sectional survey data collected before and after the crisis. Considering that children in different regions were differently exposed to the shock, we believe that crosssectional data can be used to identify the effects of the crisis, even though it is a second best option. In line with this set-up, we use a difference-in-difference strategy where we compare mortality and health outcomes of cohorts before and after the crisis in affected and unaffected districts. Alternatively, we compare younger with older children within the same families in affected and unaffected areas, to control for a number of potentially important but unobserved factors. In order to obtain an indication on the importance of a potential selection bias, we redo our impact assessment for the richest quintile only, assuming that richer households are in a better position to protect their children from crisis-related over-mortality. Hence, a potential bias due to selectivity should be reduced.

Our assessment indicates that the net impact of the crisis was surprisingly low. Underfive excess mortality must have been below 10,000 deaths, confounding the high-end estimates proposed by some NGOs and international organisations. In addition to the lower than expected mortality impact, we also do not find any general and lasting loss in weight or height of children below the age of five. Nevertheless, if we disaggregate our sample population further by age and gender, we do find some nutritional impact. The disaggregated results are, however, not uniform but document a positive, as well as negative effect of the crisis, where the positive effects are probably the result of both selective mortality and effective, compensatory aid interventions.

Building on existing qualitative studies, the present paper offers an early rigorous quantitative analysis of the effects of the 2002 food crisis on child mortality and nutrition. Thus, we hope that this analysis contributes to a better understanding of the consequences of this crisis and enhances an evidence-based debate.

The remainder of this paper is structured as follows: section 2 provides a brief review of the relevant literature. Section 3 outlines the key features of the 2002 food crisis. Section 4 presents the empirical strategy and data used for analysis. Section 5 discusses the results. Section 6 concludes.

\section{$2 \quad$ A Review of the Relevant Literature}

Whilst there is vast medical literature discussing a variety of negative effects of mal- and undernourishment on the physical and cognitive development of children, the review of the literature as presented below will be more concentrated. Related to the geographic location of this analysis, the focus of the reviewed empirical work rests on the African continent. Even though we will make reference to recent research on the influence of the overall

\footnotetext{
${ }^{8}$ See e.g. Yamano et al. (2005), Grantham-McGregor (1995), and Keenan (2002).
} 
macroeconomic situation on child mortality and health, the focus will be on empirical work analysing the impact of agricultural shocks, crop failure and drought more specifically.

Recently, a number of studies analysed the impact of macroeconomic shocks on child mortality and health in different low income settings. Pooling data from the Demographic and Health Surveys (DHS) of 59 low income countries, Baird et al. (2007) analyse the influence of macroeconomic shocks on infant mortality and find a strong negative association between infant mortality and (the stationary component of) per capita GDP. Furthermore, they also conclude that female infants are more vulnerable to changes in aggregate income, highlighting a significant gender bias. The findings by Baird et al. (2007) are echoed by Ferreira and Schady (2009) and by more refined and in-depth country studies in India (Balothra, 2010) and Peru (Agüero and Valdivia, 2010). The results by Agüero and Valdivia (2010) in particular are interesting as their analysis, similar to our work, is also based on country specific DHS data. Here, the authors use mother-fixed effects as a key identification strategy and find that past macroeconomic crises in Peru led to an increase in infant mortality ${ }^{9}$ and child malnutrition. Also, the use of antenatal care declined significantly as a consequence of the crises.

Focussing on the impact of food shortages more specifically, comprehensive analysis has been conducted in a series of works in Zimbabwe. Hoddinott and Kinsey (2001) and Hoddinott (2006) investigated the impact of various droughts on child growth in Zimbabwe. While they find no effect on children older than two, their results suggest a (probably permanent) loss of 1.5 to $2 \mathrm{~cm}$ of growth for children aged between 12 and 24 months at the time of the event. They also show that children from poorer households suffered disproportionately more from such crises, not only in terms of nutrition but also in terms of school attainment.

Also in Zimbabwe, Alderman et al. (2006) study the long-term consequences of early childhood malnutrition. Their analysis focuses on the impact of civil war and drought shocks experienced by Zimbabwean children under the age of three and their subsequent height and educational attainments as young adults based on panel data of 665 children from the years 1983/4, 1987 and 2000. Using an IV strategy and controlling for mother-fixed effects, they find that due to the transitory shocks, children lost $3.4 \mathrm{~cm}$ of height by the time they reached adolescence.

Building on the works by Alderman et al. (2006) and Hoddinott and Kinsey (2001), Dercon and Porter (2010) went back to the 1984 famine in Ethiopia. Concentrating on the long-term implications of the 1984 shock, they found that children aged 3 and below were at least $3 \mathrm{~cm}$ smaller than older cohorts by the time they reached adulthood. Their work thereby confirms the findings of earlier studies and also strengthens the evidence for the persistent implications of negative childhood events. In earlier work on Ethiopia, Yamano et al. (2005) also examine the effects of harvest failure on children's growth and find effects similar to the ones cited in the research on Zimbabwe, documenting a loss of growth of about $2 \mathrm{~cm}$.

Similar to Alderman et al. (2006), Akresh and Verwimp (2006) also assess the effects of crop failure and civil war on children's health, in this case in Rwanda. Their methodology is close to the one applied in this paper; they use variation in the intensity of these shocks over provinces and birth cohorts in order to identify the potential effects. While the authors find no impact of these events on the health status of boys, girls in the affected regions are significantly negatively affected with their height-for-age z-scores being 0.72 standard deviations lower. An alternative study focusing on Côte d'Ivoire (Jensen, 2000) investigates

\footnotetext{
${ }^{9}$ A 10 per cent decrease in GDP is estimated to lead to a 2.7/1000 increase in IMR (Agüero and Valdivia, 2010).
} 
whether children living in regions frequently exposed to adverse weather shocks are subject to lower investments in education and health. Using household data collected between 1985 and 1988, Jensen finds that children, in particular with respect to their nutritional status, are significantly negatively affected by adverse agricultural shocks.

The studies presented so far clearly indicate a negative influence of an aggregate income shock more generally and of food shortages more specifically. However, even though less numerous, there are also a few cases where climatic shocks were found to have had only moderate or even insignificant effects on children's health. Investigating a macroeconomic shock, Strauss et al. (2002) analyzed the impact of the 1997 economic crisis in Indonesia (which also led to increasing food prices) on child health outcomes and found that three years after the crisis children were not substantially worse off in respect to their health or income poverty than they were before the crisis. Contrary to expectations, some even seem to have been better off.

With respect to food crises more specifically, De Waal et al. (2006) looked at child survival during the 2002/2003 drought in Ethiopia, which was probably the worst in the recent history of the country with more than 13.2 million people affected. Although descriptive results of the analysis using data from the 2004 Ethiopian Child Survival Survey suggest that child mortality was higher in affected areas, a more detailed review using multivariate regression, leads the authors to conclude that the stated differences are more likely to be attributable to the persistently adverse conditions in these areas than to the immediate impact of the 2002/2003 drought (de Waal et al., 2006).

The validity and strength of catch-up effects in the aftermath of a crisis, particularly when specific interventions are taken to counteract the negative consequences of short-term severe malnutrition, is still controversially discussed in the literature. Ruel et al. (2008) are very pessimistic on ex-post interventions. They show that in Haiti stunting, wasting and underweight were on average 4 to 6 percentage points lower in communities that participated in preventative child health and nutrition programmes compared to communities enrolled in recuperative programmes. Also, Hoddinot (2008) disputes that catch-up is possible. However, Yamano et al. (2005) emphasize that food aid can, in therory, compensate the negative effects, but that inflexible targeting, endemic poverty and low maternal education often keep stunting at high levels despite such interventions. Grantham-McGregor (1995) would probably also agree with that as she argues that developmental improvements can occur after acute periods of malnutrition only in the context of vastly enriched environments. Empirically, the work of the English and Romanian Adoptee Study Team documents that Romanian orphans, who prior to their adoption in the UK were reared in extremely poor conditions, experience a high level of catch-up growth indicating a tendency for rapid recovery once normal environmental conditions are established in contrast to the privation which caused the initial deficit (Keenan, 2002).

Hence, in summary, the review of the literature does suggest a strong negative influence of severe food deprivation on child health. However, being optimistic, with appropriate interventions and catch-up, this negative effect could potentially be compensated or even reversed.

\section{The 2002 Food Crisis in Malawi}

Prior to the food crisis in 2002, the country had already been in a recession, hitting in particular the agricultural sector causing low commodity prices. In addition, the economic 
downturn led to a stark decline in employment opportunities and falling real wages, both in the formal and informal sectors. Hence, already before the onset of the food crisis, the population, especially in rural areas, was increasingly vulnerable with very little to fall back on.

Despite the difficult macroeconomic situation, the immediate trigger of the food crisis, however, was climatic. In February 2001, strong rainfalls led to localised flooding in about half of the districts of the country (FEWSNET, 2001a), which consequently caused an overall crop shortfall, reducing the national maize production by 32 per cent in 2001 (FEWSNET, 2001b) (see Figure 1).

[Figure 1 about here]

In addition to the comparatively low production figures, the national maize and grain reserve was also almost depleted. ${ }^{10}$ Considering the low production figures and the decline of the Strategic Grain Reserve, reports of a looming food crisis were already circulating in August 2001, leading the government to order 150,000 metric tons of maize from South Africa. Due to price increases and adverse exchange rate movements however, only 134,000 metric tons were purchased in the end. The actual delivery was then severely delayed by logistical constraints and competition with the neighbouring food-deficit countries, Zimbabwe and Zambia. ${ }^{11}$ When, in November 2001, bi- and multilateral donors also suspended their aid programmes due to governance concerns and increasing tensions with the government, the nutritional situation in the country was precarious. Nevertheless, it was only by the end of February 2002 that the President of Malawi finally declared a state of disaster. Donor responses to this emergency signal were reserved, with the first emergency food aid deliveries arriving only by April 2002 when the crisis had already passed its climax. Taking a look at the price developments at the time (Figure 2), the peak of the crisis was reached around January $2002 .^{12}$

[Figure 2 about here]

With respect to the impact of the crisis, as already mentioned, there are no official figures on excess mortality at the time. The same is true for the nutritional situation. On this, only sporadic and incomplete data is available. The nutrition surveys commissioned by 'Save the Children UK' - a British NGO - in December 2001 and February 2002 reported an alarming increase in the prevalence of global, acute malnutrition $(\mathrm{WHZ}<-2)$ among children aged between 6 and 59 months in Salima district (Central Region). Within the space of two months apparently the prevalence in the district more than doubled, rising from 9.3 to 19.0 percent

\footnotetext{
${ }^{10}$ In August 2000, the government was advised to sell about two-thirds of its reserves (about 120,000 metric tons) as the stock held at the time was found to be excessive in light of positive production estimates. One year later, at the onset of the crisis in August 2001, there were nearly no reserves left in stock.

${ }^{11}$ The ordered maize was expected to be delivered at a rate of 50,000 metric tons per month and thus should have arrived by December 2001 at the latest. But, since imports were deferred, only 94,000 tons had arrived in Malawi by April 2002.

${ }^{12}$ Prices displayed in Figure 2 are inflation adjusted consumer prices. Producer prices are much lower due to the high market power of traders making use of information asymmetries and high transaction costs. Maize market prices in Malawi follow a cyclical pattern with a drop in prices after the harvest in June/July and a significant increase at the beginning of the year in January/February, the high point of the lean season.
} 
(Devereux, 2002a). However, arguably due to imediate aid interventions, malnutrition decreased again from March 2002 onwards, and in June 2002 rates seem to have been down to 9.7 percent again (Taifour, 2002). A further reduction was the recorded by September 2002 when malnutrition dropped to 3.8 percent (Taifour, 2002). Even though it is difficult to disentangle the how much of the short-term increase reported is to be attributed to lean-season conditions and how much added on due to the crisis, the figures still point to a precarious situation at the time. Furthermore, even though the September estimate coincided with the middle of the post-harvest season, it is likely that food aid positively contributed to mitigate the effects of the crisis, despite the initially cautious responses by donors. Table 1 shows that the emergency operation (EMOP) coordinated by the World Food Programme (WFP) and a consortium of NGOs, was quite successful, with food aid distribution close to target at least with respect to the number of beneficiaries reached.

[Table 1 about here]

\section{$4 \quad$ Empirical Strategy and Data}

\subsection{Specification and Variables}

As we highlighted in the introduction, the aim of this study is to assess the net impact of the 2002 food crisis on the health of children affected. Based on the data used for analysis, we are limited to considering only the immediate, short-term effects occurring up to two years after the event.

One of the main problems when studying the impact of the food crisis, or any other shock, is to create a causal link between the event and the effects, i.e. to bridge the attribution gap. One way to address this issue is to construct a setting that comes close to a natural experiment, i.e. in which exposure to the food shock can be considered exogenous. In order to obtain estimates close to the 'causal' effect of the crisis, we exploit the regional disparity in the severity of the crisis together with the variation in health outcomes over time and space retrieved from the data. The variation in health outcomes is based on surveys undertaken before and after the crisis, i.e. in 2000 and 2004. On the basis of this data, we construct a difference-in-difference (DID) estimator that, under certain conditions which will be discussed below, measures the impact of the food crisis on these outcomes. The standard estimation equation, thus, reads as follows:

$y_{i}=\beta_{0}+\beta_{1} C_{i}+\beta_{2} M_{i}+\beta_{3} H_{i}+\eta_{n}+\delta_{1} d T_{n}+\delta_{2} d S_{t}+\delta_{3} d S_{t} d T_{n}+u_{i}$,

where $y$ represents the outcome of interest, which in this paper is twofold. First, it will constitute the discrete observation of whether a child died or not, which is assumed to represent the latent variable of the probability of death. Alternatively we will look at the influence on the child's health status, which in this case will be limited to changes in children's anthropometry. This is represented by three different z-scores, height-for-age 
(HAZ), weight-for-height (WHZ) and weight-for-age (WAZ), ${ }^{13}$ which are commonly used indicators measuring malnutrition prevalence. ${ }^{14}$ The subscript $i$ indicates that the outcome varies per individual, $n$ by district and $t$ by time period. With $T$ representing the treatment group, the dummy $d T$ captures possible permanent differences between the affected and nonaffected regions, the dummy $d S$ indicates the survey year $(2000=0,2004=1)$ and thus is a time-effect absorbing aggregate factor that would cause changes in the outcome variable over time for all observation units, even in the absence of a shock or intervention. The effect of interest is the so-called treatment effect, $\delta_{3}$, which is associated with the interaction between belonging to the treated group and the time effect. More precisely, it captures the difference in means within the treatment and control group before and after the crisis and thus provides an estimate of the impact of the food shortage on the respective outcome variable.

In order to increase the precision of the estimate, a number of control variables have been included in the specification, accounting for potential observable differences between the treatment and control group. $C$ is a vector of child characteristics, including gender, birth size, whether the child is a twin and the number of months the child was breastfed. Concerning this latter regressor, the breastfeeding duration could be considered endogenous, for example in a scenario where women extend their working time and consequently reduce breastfeeding to cope with the shock. In light of these potential linkages we have tested for the presence of an endogeinity bias introduced in our results if breastfeeding is included in our regressions, however we do not find any indication of a potential endogeneity bias resulting. For the regressions on mortality the vector $C$ further controls for the birth order of the child and short birth spacing, represented by a dummy variable. Concerning the birth order, lower and higher order children are commonly associated with a higher risk of mortality. Analogue also children received in short intervals are more likely to die at very younger ages. Thus, the inclusion of these regressors aims to increase the precision on the crisis-induced effects. In $M$ we include information about the mothers, i.e. the years of education, the marital status of the mother, and her age at the birth of the child. A number of studies (e.g. by Miller et al., 1992; Mwabu, 2009) have found a 'U'-shaped relationship between maternal age at birth and child mortality. Young and old mothers have shown to exhibit higher risk of mortality due to immature or declining reproductive systems and resources. The parabolic relationship could not be confirmed for our data. For the analysis of the anthropometric measures, $M$ also includes the respective $\mathrm{z}$-score values of the mother. The rationale behind this is that children that were breastfed during the period of the crisis may have been protected from the shock, relying on the mother's constitution. On the other hand, breastfeeding mothers may have suffered more than other women by sharing their 'resources' with their babies. Hence, it is important to control for both - breastfeeding status of the children and mothers' z-scores. The vector $H$ contains household specific information, i.e. the wealth category, whether the household is engaged in agriculture, whether the head of the household is a woman, the

\footnotetext{
${ }^{13}$ Height-for-age (HAZ) measures skeletal growth and is considered to be a reliable indicator of long-standing malnutrition in childhood. Weight-for-height (WHZ) is a measure of the deficit in tissue and fat mass and is sensitive to temporary food shortages and episodes of illness. Weight-for-age (WAZ) is a broader measure and does not discriminate well between temporary and more permanent malnutrition (WHO, 1995).

${ }^{14}$ However, here it is important to note that there are different types of malnutrition - the most common being protein-energy malnutrition, which is commonly reported during food crisis and famines (Kloos and Lindtjorn, 1994). The health consequences of protein-energy malnutrition include stunted growth, body wasting, retarded mental development and high mortality of young children. Anthropometric measures, such as height-for-age (HAZ), weight-for-height (WHZ) and weight-for-age (WAZ), are typically not perfect indicators to measure nutritional shortfalls (Kloos and Lindtjorn, 1994), nevertheless they are commonly used.
} 
number of household members and the number of children under five. $\eta_{n}$ are district-fixed effects to control for both observed and unobserved time-invariant differences across regions.

To estimate child mortality we use a linear probability model. This method has been given preference over a logit or probit estimation since, with the latter two methods, standard errors of the interaction terms are not correctly estimated in standard statistical packages and would thus have to be corrected for (see Ai and Norton (2003) for a more detailed discussion). The use of the linear probability model obviously has the problem that it assumes a linear distribution of the probabilities. However, given that we are primarily interested in the interaction effect, we accept this austerity.

The children's z-scores are calculated based on the 2006 WHO reference standards for child growth. The z-score for height-for-age is obtained by subtracting the median height in the reference population of a child of the same sex and age in months from the child's height, and dividing it by the standard deviation of the height in the reference population, also for a child of the same sex and age. The weight-for-age and weight-for-height z-scores are defined analogously, except that the standardization is done using the reference population median and standard deviation of the weight of children of the same sex, age and height. Since the zscore of the anthropometric measures are continuous variables with a distribution close to normal, the standard OLS technique is used for estimation.

It should be noted that due to potential measurement and reporting errors, the estimates on child mortality are likely to be downwardly biased. The incidence of child mortality is usually underreported. The anthropometric z-scores, and in particular the weight-for-age and weight-for-height z-scores, are probably also affected by measurement error. The data used for calculation of the z-scores does not, for instance, include information on the existence of oedema at the time of the measurement, which means that for the calculation it was assumed that the children had no oedema and, hence, z-scores on WAZ and WHZ are potentially overestimated as oedemas cause a weight increase.

To account for structural heterogeneity, our analysis will concentrate on the impact in rural areas only, as these areas were most exposed to the crisis. Further disaggregating the potential impact, we estimate separate models by gender and age of the children. The age cohorts considered will be 0 to 6 months, 6 to 12 months, 12 to 24 months, 24 to 36 months, 36 to 48 months and 48 to 60 months. In order to obtain an indication of the influence of selectivity, the model is also re-estimated for children from households in the richest wealth quintile only.

The difference-in-difference strategy outlined above accounts for a range of potential observable differences, however, differences in unobservable variables (e.g. genetic endowment etc.) are not accounted for and could significantly bias the results. In order to address this concern, we will use an alternative specification where we compare children of different age groups with the same mother in affected and unaffected districts. This allows us to control for maternal-fixed effects, i.e. all mother-specific heterogeneity is held constant. This should largely reduce the potential unobservable variable bias. In this case the estimation equation reads as follows:

$y_{i}=\beta_{0}+\beta_{1} C_{i}+\eta_{j}+\delta_{1} d K_{i}+\delta_{2} d K_{i} d T_{n}+u_{i}$

where $j$ indices variation by mothers and $\eta_{j}$ stands for the mother-fixed effect. $d K$ is a dummy for children born between 2000 and 2003, thus at the most crucial age for later development (from conception to 24 months) at the time of the crisis. The treatment effect of interest is $\delta_{2}$, 
i.e. being a member of the birth cohorts 2000 to 2003 in affected districts. To estimate the mother-fixed effects specification, we only use the post-treatment data, i.e. the DHS for 2004.

\subsection{Identification}

The separation of the treatment and control groups is obviously a central issue when using difference-in-difference estimation (see e.g. Angrist and Kruger, 1999). Particularly, the choice of an appropriate control group is important (see e.g. Abadie et al., 2007; Bertrand et al., 2002; Kubik and Moran, 2003). In an ideal set-up, the selection of the treatment and counterfactual groups would be based on a measure of food availability across space at the time of the crisis. In the absence of such information, maize production figures could be a sensible alternative. However, looking at the production levels over the years (see figure 1), even though production slumped in 2001/2002, more severe drops had been experienced in earlier years (e.g. 1992, 1994 or 1997). Considering that these drops did not result in comparable crises, the 2002 crisis was probably not a crisis in terms of overall output but rather a more complex issue of availability. Therefore, overall production levels do not seem to be a useful indicator in this context. Other papers investigating effects of drought on children's health often used rainfall data (e.g. Akresh and Verwimp, 2006). We refrained from using such data for identification for two reasons: first, the available rainfall data is incomplete and, second, not all areas that were flooded in early 2001 experienced food shortages, as a number of other factors, such as crop choices and the possibility for crossborder trade, mitigated the effect of the food crisis. Instead we decided to use the consumer price for maize as an indicator. This is considered to be a suitable indicator to measure availability or food shortage across regions for two reasons. First, in the absence of major market distortion, prices signal scarcity. Second, the variation in price levels across districts does, on the whole, tie in with a number of anecdotal and qualitative reports on food-scarce locations.

[Figure 3 about here]

For instance, at the market in Chitipa in the North of the country (see Figure 3 above) maize was sold at much lower prices during the crisis than in the other two regions and indeed the majority of the northern districts did not report any severe food shortages.

Thus, to identify the crisis areas, we computed an annual average of the monthly maize market prices from monitored markets throughout the country. The average price threshold was then set at $20 \mathrm{Kw} / \mathrm{Kg}$, as this was reported to be the highest price at which the governmental organisations would buy maize during the crisis year. On the basis of this limit, districts with an average maize market price above $20 \mathrm{Kw} / \mathrm{Kg}$ were sorted to the 'treatment group', while the remaining areas were assigned to the counterfactual. Through this mechanism, the following regions were identified as being affected by the food crisis: Nkhotakota, Ntchisi, Dowa, Mchinji, Salima, and Dedza in the Central Region and Mangochi, Machinga, Zomba, Phalombe, Mulanje, Thyolo, Balaka and Mwanza in the Southern Region. The other districts, predominantly in the Northern Region, were classified as not-affected.

One underlying assumption when applying a difference-in-difference methodology, which is particularly relevant in this set up, is the absence of the so called 'Ashenfelter dip'. This means that both treatment and control areas have to follow parallel trends. Thus, it has to be verified that areas affected by the crisis did not experience a negative shock prior to 2002 
which would make them more prone to the actual event. This is confirmed in our case. Figure 4 shows that average maize prices followed the same trend before the crisis.

[Figure 4 about here]

To test the pertinence of the identification strategy, a placebo test ${ }^{15}$ was carried out on data from the 1992 and 2000 Demographic and Health Surveys (DHS). As expected, no differential impact could be identified, thus increasing confidence in the method chosen (see Table A2 in the appendix). To further verify the sensitivity of the results, we use a number of alternative means to distinguish between the treatment and control group. First, instead of using a dummy variable identifying the treatment and control group, we introduce the logarithm of the yearly average maize market price directly in the specification. This increases variation but also slightly changes the interpretation of the results (this will be discussed further in section 5). The alternative equation to be estimated in this case reads as follows:

$y_{i}=\beta_{0}+\beta_{1} C_{i}+\beta_{2} M_{i}+\beta_{3} H_{i}+\delta_{1} \log \left(P_{n t}\right)+\delta_{2} d S_{t}+u_{i}$,

where the treatment indicator has been replaced by the logarithm of $P$, the average maize market price, in the respective district prior to the crisis in the baseline year 2000 and the crisis prices. Second, we use the classification from the emergency assessment carried out by the FAO and WFP in May 2002 immediately after the high point of the crisis was reached.

\subsection{Data}

In order to implement the strategy described above, we use pooled cross-sectional data from the DHS conducted in Malawi in 2000 and 2004, which are representative at national, regional and the rural and urban level. For the present analysis, we use information on children aged 5 or below, their respective household and mother characteristics. The combined dataset for both years includes in total 19,619 observations, 9,842 collected in 2000 which constitutes the baseline data, and information on 9,777 children collected in 2004 . The data used for analysis was thus collected two years before and after the crisis respectively. The data does not show any systematic underreporting of child mortality. The response rate of the anthropometric module was 77.5 per cent in 2000 and 74.8 per cent in 2004 . Here also we did not find a systematic bias for non-response.

The descriptive statistics of our sample are presented in the appendix (Table A1). Comparing affected and non-affected districts over time allows getting a first naïve estimate of the health effect of the crisis. It can be seen that the percentage of children that died before the age of 5 dropped from 14.5 per cent to 10.3 per cent in affected districts and from 13.0 per cent to 9.5 per cent in non-affected districts. Thus, the reduction in child mortality in the affected areas, at -4.2 points, is slightly higher than in non-affected areas (-3.5 points). The anthropometric measures WAZ, HAZ and WHZ show diverging trends. While the WAZ has improved over time in both groups, even slightly more so in affected areas (although from a

\footnotetext{
${ }^{15}$ We used the data sets of 1992 and 2000 instead of 2000 and 2004 and implemented otherwise the same identification strategy. The test consists in verifying that the treatment effect, i.e. the interaction of the year effect - which in this test refers to the year 2000 - and the treatment area effect is insignificant.
} 
lower initial level), the HAZ fell in the affected districts, but increased slightly in the nonaffected districts. In the base year, chronic malnutrition (HAZ) is slightly higher in affected areas. Acute malnutrition, i.e. WHZ, improved quite substantially, again in both affected and non-affected districts, with non-affected districts actually doing worse in the base year.

The descriptive statistics in Table A1 also highlight the extent to which children in affected and non-affected districts differ, i.e. whether their characteristics developed differently over time. There is no difference in the share of boys in both areas. Breastfeeding increased over the years: children in non-affected areas were fed on average 0.35 months and 0.70 months longer in 2000 and 2004 respectively. The size of the children at birth seems to have increased over time, with children in the non-affected districts being slightly larger. Mother's education improved in both groups by about 0.7 and 0.5 years of schooling in the affected, respectively in the non-affected areas, which is probably a pure cohort effect. The lower average number of years at school in affected districts suggests again that households in these areas are on average slightly poorer than in non-affected districts. This is also reflected by the larger share of households falling into the group of the 40 per cent poorest households in terms of the possession of assets in affected regions. Mothers' anthropometric measures are not significantly different in both years but are slightly worse in affected areas. Interestingly, the BMI shows that on average the population still lies within the normal range of 18.5 to 25 points. In 2004 more households were engaged in agriculture compared to 2000. Average household size declined in both groups over time and is slightly lower in affected districts compared to non-affected ones. The structural differences between both groups highlight the importance of including control variables in the difference-in-difference estimation. Regarding the unobservable factors that are unrelated to the crisis but correlated with health outcomes, we must assume that these did not change differently for both groups in the period under study. The introduction of mother-fixed effects should reduce this potential unobserved heterogeneity bias.

Using the data described, it has to be verified whether the sample size is large enough to detect excess mortality of the order of magnitude mentioned in the media during and after the crisis. Taking the standard significance level of 95 per cent (one-sided) and making the most conservative assumption about the variance in mortality in the total population, power calculations show that we can detect excess mortality between the affected and non-affected areas of 8,937 death events and more. Smaller differences would need a larger sample to be detected with certainty. Hence, the sample is at least large enough to confirm or reject the high estimates put forward by NGOs and international organisations.

\section{Discussion of the Results}

\subsection{Effect of the Food Crisis on Child Mortality}

The results of the estimated linear probability model as described in Section 4.1 are presented in Table 2 .

[Table 2 about here]

Column (1), as already suggested by the descriptive evidence above, shows that rural areas affected by the food crisis did not experience higher child mortality than the nonaffected areas controlling for general time and area effects. Likewise, this result does not 
change if we introduce a large set of control variables and district-fixed effects in the regression (see columns (2) and (3)). The result also holds if we use our mother-fixed effects estimator (see Table 6). This suggests that the food crisis did not have an impact on child mortality in the order of magnitude put forward by some NGOs. However, if we disaggregate these results further by age group, we see that the overall results are subject to considerable heterogeneity. The estimates suggest that during the first six months of life, boys exposed to the crisis experienced an increase in their mortality risk by about 8.3 percentage points. In contrast, girls in the same age group exposed to the crisis surprisingly saw a decline in their mortality risk. Below we discuss what may have led to improvements in mortality conditions, but the difference between boys and girls per se is plausible, since it is well known that during infancy male mortality is slightly higher than female mortality, rendering it likely that male infants are also more vulnerable to hunger and disease than female infants. In addition, there are number of behavioural factors that have been reported in the Malawian context, which may further explain why girls were less vulnerable to the crisis than boys. Ashorn et al. (2002), for instance, indicate that sex-specific vaccination effects and a matrilineal family organisation might favour girls. From the DHS data we also observe that the incidence of regular check-ups after birth is slightly higher for girls than for boys. In line with the higher incidence of health checks, girls also more often receive a vitamin A supplement within the first two months after birth than boys. ${ }^{16}$ Finally, our results also indicate a statistically significant increase in the probability of death for boys aged between 36 and 48 months.

\subsection{Effect of the Food Crisis on Child Anthropometry}

Tables 3 to 5 show the results for the three anthropometric measures: WAZ, HAZ and WHZ. Again in columns 1 to 3, we present first the results of the regressions, in which we only use the time and area effects and the corresponding interaction term. Except for the weight-for-age z-scores, we do not find any significant impact of exposure to the crisis on malnutrition. This is also confirmed by the estimates of the mother-fixed effects specification (Table 6). The effect on the weight-for-age z-scores is even positive, i.e. it suggests a slight improvement of the nutritional status.

However, as we have already argued in the previous section, these estimates seem to be subject to considerable heterogeneity. Therefore, we will concentrate our discussion on the disaggregated gender and age differentiated results. Looking at the weight-for-age z-scores, which are used more generally as a measure of the degree of underweight, the results obtained are interesting as they highlight a quite strong gender divide. While male children, particularly during their first two years of life, seem to have increased rather than decreased their weight in the context of the crisis, female children seem to have suffered. Particularly girls aged between 36 and 48 months were found to have lost 0.216 standard deviations compared to their counterparts in non-affected areas. The findings are also largely confirmed if we look at the weight-for-height z-scores, which are a commonly used measure of acute malnutrition. Here again we find that boys from 6 months up to the age of 2 were not adversely affected, on the contrary, their score increased, while female children aged between 1 and 3 years old lost between 0.286 to 0.321 standard deviations.

\footnotetext{
${ }^{16}$ According to the 2004 DHS, 22.9 percent of baby girls were taken for an after-birth check-up compared to 21.8 percent of the baby boys. Likewise, 41.8 percent of the baby girls received a vitamin A supplement in their first two months of life compared to a slightly lower figure of 40.8 percent for baby boys. These differences are significant at a level of 12 percent and 26 percent respectively.
} 
In sum, the above assessment shows that the male children were more likely to die during the crisis. However, the children that survived the crisis seem to have been those with particularly good anthropometric conditions which may in turn explain the slight improvement of anthropometric outcomes observed for the cohort of survivors. It could also be a sign that food aid targeted at particularly vulnerable groups, after the first mortality had set in, was highly effective. For girls, we do not observe higher mortality (and thus selection), but we do see increased acute malnutrition, in particular in girls between 1 and 2 years old. Whether this result is driven by an intra-household distribution of food in favour of boys is difficult to say, though this would be inconsistent with the higher mortality observed among some male age groups. Finally, for the surviving cohorts, we find for some age groups gains in height-for-age and thus long-standing malnutrition, which again would support the idea that emergency food aid was very effective and in the end even led to some lasting improvement in the nutritional status of these children. Given the low initial nutritional level this is not implausible.

[Tables 3-6 about here]

\subsection{Caveats}

In this section we critically discuss some of the assumptions underlying the approaches used to derive the results presented in the previous section. Thereafter, we test, where possible, the robustness of our results relying on alternative assumptions.

First, when using a difference-in-difference estimator one has to assume that the changes in the outcome variable in the absence of a shock would have been exactly the same in both, the affected and non-affected districts; or in other words, that the treatment and control group follow constant and parallel trends in the absence of treatment. Yet, to account for the possibility of a potentially diverging trend, a number of control variables have been included in the regressions. However, we cannot, of course, exclude the possibility that there are other unobserved factors that are systematically different between the treatment and control group and that are related to changes in children's health and mortality conditions. We do try to address this concern for unobserved heterogeneity by using mother-fixed effects; however, unobserved area-specific shocks that occurred at the same time may still bias the results. For example, if in the period of study the HIV/AIDS epidemic evolved differently in the treatment and control group, then effects related to HIV/AIDS may be confounded with the effects related to the drought. Moreover, changes in outcomes may be affected not only by the shock under study but if measured with some delay also by the policy interventions that were intended to respond to the drought. Food aid that was targeted to affected districts in response to the crisis would also mitigate the health impact in affected regions compared to nonaffected regions. ${ }^{17}$ Hence, as we already emphasized in the introduction, our analysis focused on the net effect in 2004, i.e. after some coping mechanisms had already been implemented. With the data at hand, it is impossible to construct a counterfactual that looks at the potential impact without such interventions. But it would also not be helpful to answer our research

\footnotetext{
${ }^{17}$ Note that major agricultural and health programmes like the Input Factor Programmes (IFP) were rolled out nationwide with similar coverage and targeting across all districts. However, we cannot exclude the possibility that smaller NGO projects were more concentrated in affected districts.
} 
question, which ask what the actual impact on mortality and children's health has been, hence factoring in the protective measures taken at the time.

Second, from the descriptive statistics in Table A1, we know that households in the control area are slightly richer and more educated. Although we control for these variables in the regressions, it is possible that these characteristics also help households in the control group to better cope with shocks than households in treatment group. This would mean that part of the difference we see between the control and treatment group could stem from the fact that households in the treatment area are particularly vulnerable to such shocks. The vulnerability to food shocks is then not random and neither are ex-ante and ex-post coping strategies, in the sense that wealthier households would probably be better prepared to respond to such shocks through better options in production, saving, and insurance decisions. Poorer households in areas with frequent food insecurities may also be less able to smooth out income shocks because they are frequently exposed to such shocks and thus have already depleted valuable assets in the past. In either case, the treated and non-treated would respond differently to the crisis. Moreover, shocks like a drought may not actually be fully exogenous, but rather endogenous in a sense that regions prone to natural disasters and disease 'retain' mainly the poor, while the non-poor leave to more hospitable environments. Hence, the impact of the crisis is likely to be higher in affected areas than in the control areas, as the control population is more capable of dealing with covariate shocks and is less exposed to such shocks. In other words, the endogeneity of the 'severity' of the food crisis may lead to a biased estimate of its effects on child mortality and children's health. However, here again this has hardly any effect on our findings, since we are interested in the actual impact of the crisis, i.e. the counterfactual we are interested in is, "what would have been the health status and mortality of children in the affected areas if the drought had not occurred?' If people in affected areas are more vulnerable, it just means that the same crisis in non-affected areas would have had a smaller impact.

Third and last, our identification strategy would be problematic if there was substantial migration between the treatment and the control areas and if migrants had unobservable characteristics different from the population at destination and if these characteristics were correlated with the observed health outcomes. The data sources used in this paper do not allow us to study migration behaviour and flows in much detail, as they only provided information on the years lived in the current place of residence. There are also no other sources that would allow us to study migration in more detail. In our sample, 93.7 per cent of the children had been living in the same place of residence since birth. Assessing migration behaviour based on household size is difficult and might be misleading. Nevertheless, we do not find a systematic decline in household size in treated districts and an increase in control districts, which, if it had happened, could, for instance, be a sign of child fostering. A study by Makoka (2008) shows that migration is not a widely used strategy to cope ex-post with droughts or increased food prices in the context of Malawi. More generally, looking at the spatial distribution of the population retrieved from the censuses of 1987, 1998 and 2008, the proportional distribution of the population across districts remained rather stable; this is particularly true for the period 1998 to 2008. A slight decrease can only be observed in rural Zomba in the southern part of the country (-1.1 percentage points), while the population in and around Lilongwe grew by about one per cent over the ten year period (NSO, 2010). 


\subsection{Sensitivity Analysis and Robustness Checks}

To address some of the potential problems discussed above, robustness checks were performed. As discussed in section 4.2 (see specification (2)) we propose an alternative estimation strategy in which we introduce the treatment intensity directly via the maize price, controlling for district-fixed effects. This creates more variation in the treatment variable. The results are presented in Tables 7 to 10. Considering that we are using the logarithm of the maize prices, the coefficients have to be interpreted as elasticities. We find that a 10 percent increase in maize prices leads to a significant increase in the mortality risk of boys 3 to 4 years old. Also, the WAZ of girls 4 to 5 years old seems to be significantly negatively affected by the price hikes. Thus these results confirm to some extent the above finding of a higher mortality risk of affected male cohorts. It also confirms that the mortality risk to girls was not greatly affected and if it was, then more in a positive sense, but that girls experienced substantial declines in at least some anthropometric outcomes.

We re-estimated the results using even further identification strategies, e.g. by classifying the regions into tuber and non-tuber growing areas. The underlying argument is that the areas producing and consuming tuber as a staple food would not be affected by a food crisis resulting from shortages in maize. To further check the robustness of our results, we applied a separation of the treatment and control group based on the food security and vulnerability assessments carried out alternatively by the Malawi National Vulnerability Assessment Committee (MNVAC) in September 2002 and one carried out by the FAO in conjunction with the WFP in May 2002. The first two alternative identification strategies were found to have a number of drawbacks and did not yield conclusive results, mainly because the separation into tuber and non-tuber growing areas was not sharp enough and the vulnerability assessment by the MNVAC was carried out too late and thus overlapped with the start of the next harvest. Hence, the FAO and WFP assessment is the most convincing instrument. In fact, the FAO and WFP assessment was carried out very close to the high point of the food crisis. The FAO and WFP (2002) classified seven districts as facing a high severity of the food crisis: Nkhotakota, Salima, Lilongwe, and Ntcheu in the Central Region and Mangochi, Blantyre and Zomba in the Southern Region. For the estimation, these districts were defined as the treatment group, while the rest of the country was defined as the control group. The results obtained confirm a differential impact on boys and girls as highlighted by the findings above - the evidence however is weak (results can be provided by the authors upon request).

\section{[Tables 7-10 about here]}

\subsection{The Role of Food Aid}

In light of the positive effects on children's anthropometry, we have argued that this could be attributed to a lower than previously assumed impact of the crisis, selective mortality and also effective food aid. Although precise data on delivered food aid is scarce, in what follows we present a first attempt to link the observed changes in mortality and malnutrition to food assistance, which we measure by the number of beneficiaries to the total population per district. Given that provided food aid is obviously endogenous to mortality and nutrition, we have to instrument food aid. The analysis above suggests that the district-specific average maize price is an ideal instrumental variable for this purpose. Thus, we use the same specification than in Equation (3), except that we replace $P_{n}$ by food aid, as just defined, and 
instrument it by $P_{n}$. For the estimation we obviously only use the post-crisis data, i.e. the 2004 DHS, thus time effects are also dropped.

The results are presented in Table 11. Concerning the first-stage results we see that the average maize prices are indeed positively correlated with the food aid estimates, which gives further support to the identification strategy chosen in this paper. Most $F$-tests are above the required threshold of 10 (Stock and Yogo, 2002). The second-stage regressions reveal that food aid has not significantly contributed to reducing mortality. Again, considering that food aid was only delivered after the climax of the crisis and thus likely also after mortality had peaked, this finding is not necessarily counterintuitive. With respect to the results on the anthropometric measures, the results clearly indicate that food aid indeed reduced the prevalence of underweight (WAZ) among very young children (below age 1) in particular. Moreover, acute malnutrition (WHZ) could significantly be reduced across almost all age categories. These results further underpin our argument of food aid having been effective in cushioning the negative impact of the crisis.

\section{[Tables 11 about here]}

\section{Conclusion}

In this paper we took a close look at the 2002 Malawi food crisis. Non-governmental, governmental and international organisations published quite different assessments regarding the likely impact of that crisis in terms of malnutrition rates and induced excess mortality. These assessments were usually not backed up by empirical evidence or any rigorous simulation exercise but were rather the result of rough expert guesses and probably often biased by a specific political interest. We relied on representative household data collected before and after the crisis and a powerful identification strategy to come up with an assessment of the mortality and health impact of the crisis and the emergency aid that followed. Our assessment indicates that the net impact of the crisis was surprisingly low. Excess mortality in the under fives must have been much lower than the 10,000 additional death cases which were suggested by some organisations at the time of the crisis. We also do not find any general and lasting loss in weight or height in children below the age of five. Obviously, given that we rely on observational and not experimental data, our identification strategy is not without shortcomings, but none of the many robustness checks we have undertaken and discussed in this paper would be consistent with the high estimates reported at the time. What our analysis cannot answer is whether this is the case because the crisis was from the start less severe than assumed by many or whether emergency aid was just very effective. However, the more qualitative evidence we consider, including the reportedly successful distribution of food aid, and a first attempt to assess the impact of food aid using an IV approach, it seems to suggest that it is a mixture of both. What we can exclude is that the lack of a strong impact is the result of large scale migration out of affected areas.

We do find some impacts however - both positive and negative - if we disaggregate our sample population further by age and gender. We find excess mortality for boys in the 0 to 6 months and 36 to 48 months age groups. In contrast, for the male age group 24 to 36 months and, for girls, 0 to 6 months and 48 to 60 months we find under mortality. For all other age brackets below the age of 5 we do not find any significant impact. All these effects are not particularly large and we cannot fully exclude that they are driven by data inaccuracy given that the sample sizes at this level of disaggregation are not very large 
Our analysis of anthropometric outcomes indicates small gains in weight for male cohorts below the age of two that were affected by the crises. Given that we rely on repeated crosssections and not on panel data, these weight gains may simply be the effect of selective mortality, i.e. the average weight tends to increase with extremely malnourished children dropping out of the sample. It could also be a sign that food aid targeted at particularly vulnerable groups and after the first mortality had set in was highly effective. For girls, where we do not observe higher mortality (and thus selection), we do indeed see increased acute malnutrition, in particular in girls between 1 and 2 years old. Whether this result is driven by an intra-household distribution of food in favour of boys is difficult to say, though this would, at the least, be inconsistent with the higher mortality observed among some male age groups. Finally, for the surviving cohorts, we find for some age groups gains in height-for-age and thus improvements in long-standing malnutrition, which again would support the idea that emergency food aid was very effective and in the end even led to some lasting improvement in the nutritional status of these children. Given the low initial nutritional level this is not implausible.

We end this analysis with a final word of caution. We only considered the potential short and medium-term health impacts of the food crisis and had to ignore the potential long-term effects. Although it is well known that even temporary food shortages can affect children's cognitive development, these effects will only be visible once affected and non-affected cohorts complete their schooling and enter the labour market. Future research has to investigate this issue.

\section{Appendix}

[Tables A1 - A2]

\section{References}

Abadie, A., A. Diamond, and J. Hainmueller (2007) 'Synthetic Control Methods for Comparative Case Studies'. NBER Working Paper 12831. Cambridge, MA: National Bureau of Economic Research.

Agüero, J., and M. Valdivia (2010) 'The Permanent Effects of Recessions on Child Health: Evidence from Peru'. Paper presented at the XIV. Meetings of the LACEA/IADB/WB/UNDP Research Network on Inequality and Poverty. April 9, 2010.

Ai, C., and E.C. Norton (2003). Interaction terms in logit and probit models. Economics Letters, 80:123-129.

Akresh, R., and P. Verwimp (2006) 'Civil War, Crop Failure, and the Health Status of Young Children’. HiCN Working Paper No. 19. Brighton: University of Sussex.

Alderman, H., J. Hoddinott, and B. Kinsey (2006) 'Long term consequences of early childhood malnutrition'. Oxford Economic Papers, 58:450-474.

Angrist J.A., and A.B. Krueger (1999) 'Empirical Strategies in Labor Economics'. In O.C. Ashenfelter and D.A. Card (eds) Handbook of Labor Economics (Vol. 3A), pp. 12771366. Amsterdam: Elsevier. 
Ashorn, P., K. Maleta, M. Espo, and T. Kulmala (2002) 'Male biased mortality among 1-2 year old children in rural Malawi'. Archives of Disease in Childhood, 87: 386-387.

Baird, S., J. Friedman, and N. Schady (2007) 'Aggregate Income Shocks and Infant Mortality in the Developing World'. World Bank Policy Research Paper 4346. Washington DC: World Bank.

Bertrand, M., E. Duflo, and S. Mullainathan (2004) 'How Much Should We Trust Differencein-Difference Estimates?'. The Quarterly Journal of Economics, 119(1): 249-275.

Bhalotra, S. (2010) 'Fatal fluctuations? Cyclicality in infant mortality in India'. Journal of Development Economics, 93: 7-19.

Dercon, S., and C. Porter (2010) 'Live aid revisited: long-term impact of the 1984 Ethiopian famine on children'. CSAE Working Paper WPS/2010-39. Oxford: Oxford University.

De Waal, A., A. Seyoum Taffesse, and L. Carruth (2006) 'Child Survival during the 20022003 Drought in Ethiopia'. Global Public Health, 1(2): 125-132.

Devereux, S. (2002a) 'State of Disaster: Causes, Consequences and Policy Lessons from Malawi'. Report commissioned by ActionAid Malawi (13 June). Lilongwe: ActionAid Malawi.

Devereux, S. (2002b) 'The Malawi Famine of 2002'. IDS Bulletin, 33(4): 70-78.

Dorward, A., and J. Kydd (2004) 'The Malawi 2002 food crisis: the rural development challenge'. Journal of Modern African Studies, 42(3): 343-361.

FAO Statistics Division (2008) 'FAOSTAT ProdSTATA Crops (1986-2006)' (online database). http://faostat.fao.org/site/567/DesktopDefault.aspx?PageID=567 (accessed 27 July 2008).

FAO and WFP (2002) 'FAO/WFP Crop and Food Supply Assessment Mission to Malawi'. Special Report (29 May). Rome and Kampala: Food and Agricultural Organisation and World Food Programme.

Ferreira, F. H. G., and N. Schady (2009) 'Aggregate Economic Shocks, Child Schooling and Child Health'. World Bank Research Observer, 24(2): 147-181.

Ferro-Luzzi, A., S.S. Morris, S. Taffesse, T. Demissie, and M. D'Amato (2001) 'Seasonal Undernutrition in Rural Ethiopia: Magnitude, Correlates and Functional Significance'. Research Report 118. Washington D.C.: International Food Policy Research Institute.

FEWSNET (2001a) 'Malawi - Monthly Food Security Report: February 2001'. Lilongwe: FEWSNET Project.

FEWSNET (2001b) 'Malawi - Monthly Food Security Report: mid-May - mid-June 2001'. Lilongwe: FEWSNET Project.

FEWSNET (2002a) 'Malawi - Monthly Food Security Report: mid-May - mid-June 2002'. Lilongwe: FEWSNET Project.

FEWSNET (2002b) 'Malawi - Monthly Food Security Report: mid-September - mid-October 2002'. Lilongwe: FEWSNET Project

Gorgens, T., X. Meng, and R. Vaithianathan (2007) 'Stunting and Selection Effects of Famine: A case study of the Great Chinese Famine'. IZA Discussion Paper 2543. Bonn. IZA.

Grantham-McGregor, S. (1995) 'A Review of Studies of the Effect of Severe Malnutrition on Mental Development'. The Journal of Nutrition, 125:2233S-2238S.

Hoddinott, J. (2006) 'Shocks and their Consequences Across and Within Households in Rural Zimbabwe'. Journal of Development Studies, 42(2): 301-321. 
Hoddinott, J., and B. Kinsey (2001) 'Child Growth in the Time of Drought'. Oxford Bulletin of Economics and Statistics, 63(4): 409-436.

Jensen, R. (2000) 'Agricultural Volatility and Investments in Children'. The American Economic Review, 90(2) Papers and Proceedings of the One Hundred Twelfth Annual Meeting of the American Economic Association (May, 2000): 399-404.

Keenan, T. (2002) 'An Introduction to Child Development'. London: Sage Publications Ltd.

Kloss, H., and B. Lindtjorn (1994) 'Malnutrition and Mortality During Recent Famines in Ethiopia: Implications for Food Aid and Rehabilitation'. Disasters, 18(2): 130-139.

Kubic, J.D., and J.R. Moran (2005) 'Can Policy Changes be Treated as Natural Experiments? Evidence from Cigarette Excise Taxes'. NBER Working Paper 11068. Cambridge, MA: National Bureau of Economic Research.

Kydd, J., A. Dorward, and M. Vaughn (2002) 'The Humanitarian Crisis in Southern Africa: Malawi'. Submission to the International Development Committee (October). London: International Development Committee.

Makoka, D. (2008) 'The Impact of Drought on Household Vulnerability: The Case of Rural Malawi'. Mimeo. Bonn: University of Bonn.

Malawi National Vulnerability Assessment Committee and SADC FANR Vulnerability Assessment Committee (2002) 'Malawi Emergency Food Security Assessment Report'. Special Report (16 September). Lilongwe: Malawi National Vulnerability Assessment Committee.

Miller, J.E., J. Trussell, A.R. Pebley, and B. Vaughan (1992) 'Birth Spacing and Child Mortality in Bangladesh and the Philippines'. Demography, 29(2): 305-318.

Mwabu, G. (2009) 'The Production of Child Health in Kenya: A Structural Model of Birth Weight'. Journal of African Economies, 18(2): 212-260.

NSO (2005) 'Malawi Second Integrated Household Survey 2004-2005 (IHS-2)'. Zomba: National Statistical Office of Malawi.

NSO (2008) 'Consumer Price Index' (online database). http://www.nso.malawi.net/ (accessed: 27 July 2008).

NSO (2010) '2008 Population and Housing Census Final Results'. Zomba: National Statistical Office of Malawi.

NSO and ORC Macro (1993) 'Malawi Demographic and Health Survey 1992'. Claverton: National Statistical Office of Malawi and ORC Macro.

NSO and ORC Macro (2001) 'Malawi Demographic and Health Survey 2000'. Claverton: National Statistical Office of Malawi and ORC Macro.

NSO and ORC Macro (2005) 'Malawi Demographic and Health Survey 2004'. Calverton: National Statistical Office of Malawi and ORC Macro.

Roshni, M. (2007) 'Famine in Malawi: Causes and Consequences'. Human Development Report Office Occasional Paper 2007/35. New York: UNDP.

Ruel, M.T., P. Menon, J.-P. Habicht, C. Loechl, G. Bergeron, G. Pelto, M. Arimond, J. Maluccio, L. Michaud, and B. Hankebo (2008) 'Age-based Preventive Targeting of Food Assistance and Behavior Change and Communication for Reduction of Childhood Undernutrition in Haiti: A Cluster Randomised Trial'. Lancet, 371(9612): 588-595.

Stevens, C., S. Devereux, and J. Kennan (2002) 'The Malawi Famine of 2002 : More Questions than Answers'. Mimeo. Brighton: Institute of Development Studies. 
Stock, J.W. and M. Yogo (2002) 'Testing for Weak Instruments in Linear IV Regression'. NBER Technical Working Papers 0284, National Bureau of Economic Research, Inc.

Strauss, J., K. Beegle, A. Dwiyanto, D. Pattinasarany, B. Sikoki, Sukamdi, and F. Witoelar (2002) 'Economic Crisis Impacts on Children after Three Years: Evidence from the Indonesia Family Life Survey'. Mimeo. East Lansing: Michigan State University.

Taifour, H. (2002) 'Nutrition Survey Report Salima and Mchinji Districts'. Report commissioned by Save the Children UK (September). London: Save the Children UK.

WFP (2002) 'Food Shortages in Malawi: The Facts'. http://one.wfp.org/Newsroom/in_depth/Africa/sa_malawi020705.asp?section=2\&sub_sec tion $=2$ (accessed 20 $0^{\text {th }}$ July 2008).

WFP (2003) 'A Report from the Office of Evaluation: Full Report of the Real-Time Evaluation of WFP's Response to the Southern Africa Crisis, 2002-2003 (EMOP 10200)'. OEDE/2003/03. Rome: World Food Programme.

WHO (2007) 'Anthro for Personal Computers (Version 2.0): Software for Assessing Growth and Development of the World's Children' (computer software). Geneva: World Health Organisation.

WHO (2002) 'Report on Update of Health Assessment - UNFPA, UNICEF, UNAIDS, Ministry of Health and WHO' (Malawi September 2002). www.who.int/disasters/repo/8416.doc (assessed $17^{\text {th }}$ October 2009).

WHO (1995) 'Physical status: The use and interpretation of anthropometry'. WHO Technical Report Series No. 854. World Health Organization, Geneva.

Yamano, T., H. Alderman, and L. Christiaensen (2005) 'Child Growth, Shocks and Food Aid in Rural Ethiopia’. American Journal of Agricultural Economics, 87(2): 273-288. 


\section{Tables and Figures}

Table 1: Planned and Actual Distribution of Food Aid (incl. Food for Work) of the EMOP (July 2002 - June 2003)

\begin{tabular}{crrrrrr}
\hline & \multicolumn{3}{c}{ Food (MT) } & \multicolumn{3}{c}{ Beneficiaries } \\
Months & Planned & Actual & \% & Planned & Actual & \% \\
\hline Jul 2002 & 6,996 & 5,007 & 72 & 530,000 & 545,788 & 103 \\
Aug 2002 & 6,996 & 6,501 & 93 & 530,000 & 658,483 & 124 \\
Sept 2002 & 28,288 & 14,005 & 50 & $2,143,000$ & $1,294,708$ & 60 \\
Oct 2002 & 28,288 & 22,586 & 80 & $2,143,000$ & $2,068,127$ & 97 \\
Nov 2002 & 28,288 & 24,528 & 87 & $2,143,000$ & $2,334,464$ & 109 \\
Dec 2002 & 42,087 & 28,195 & 67 & $3,188,000$ & $2,339,527$ & 73 \\
Jan 2003 & 31,113 & 25,743 & 83 & $2,852,306$ & $2,403,688$ & 84 \\
Feb 2003 & 38,323 & 31,996 & 83 & $3,400,000$ & $2,879,740$ & 85 \\
Mar 2003 & 43,800 & 31,154 & 71 & $3,595,000$ & $2,831,071$ & 79 \\
Apr 2003 & 24,367 & 21,918 & 90 & $2,000,000$ & $2,855,862$ & 143 \\
May 2003 & 18,275 & 14,258 & 78 & $1,500,000$ & $2,815,148$ & 188 \\
Jun 2003 & 12,184 & 2,522 & 21 & $1,000,000$ & 890,558 & 89 \\
\hline TOTAL & $\mathbf{3 0 9 , 0 0 5}$ & $\mathbf{2 2 8 , 4 1 3}$ & $\mathbf{7 4}$ & N/A & N/A & \\
\hline
\end{tabular}

Source: WFP (2003) - Annex 2 


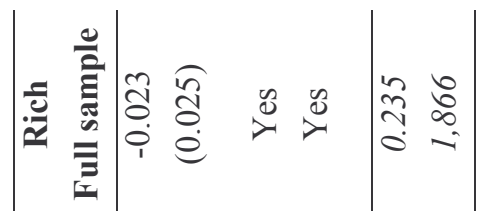

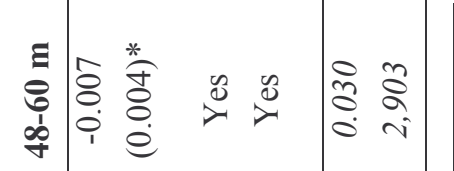

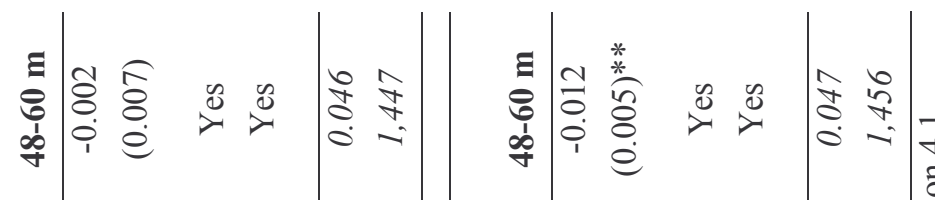

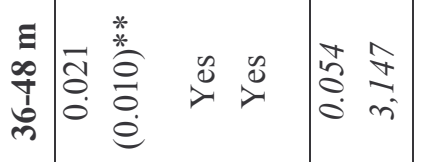

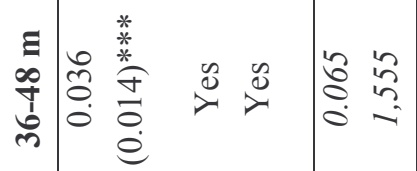

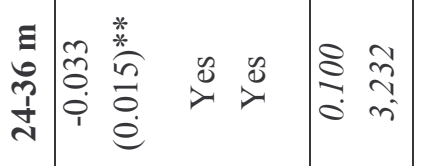

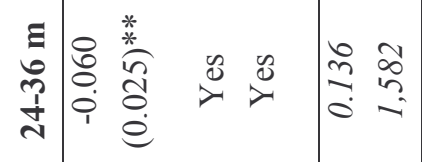

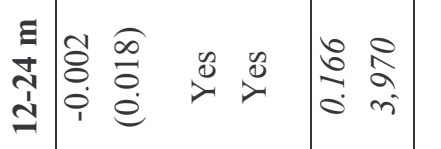

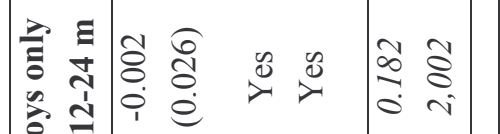

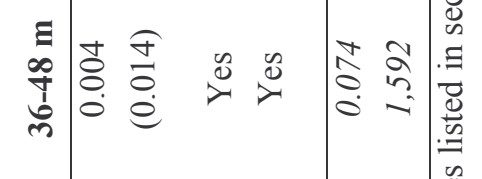

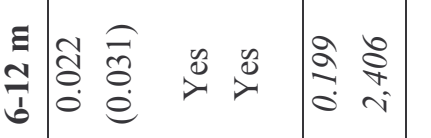

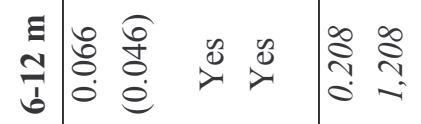

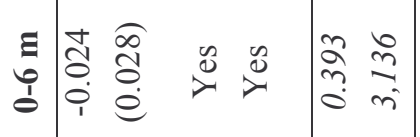

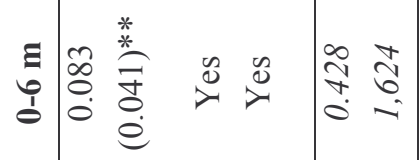

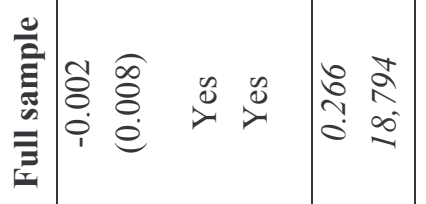

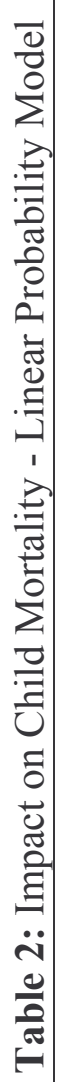

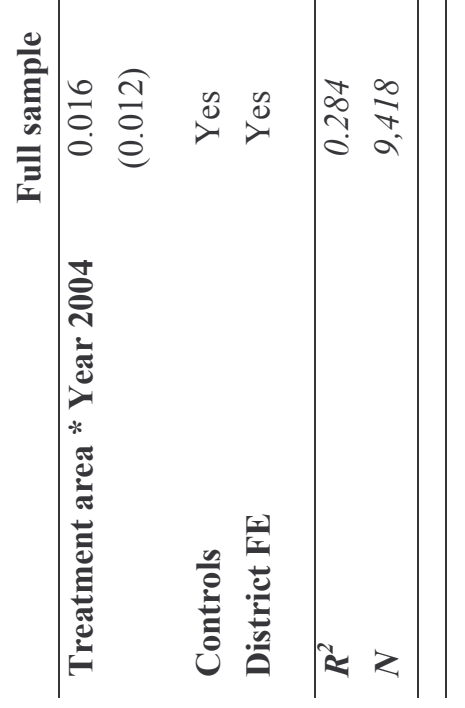

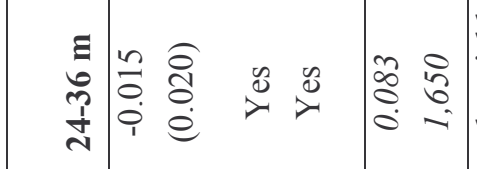

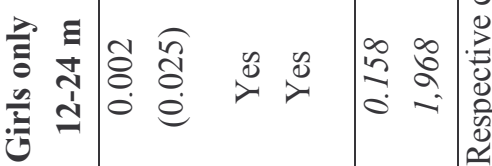

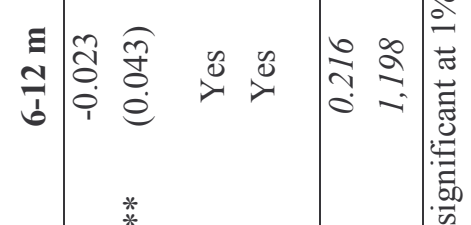

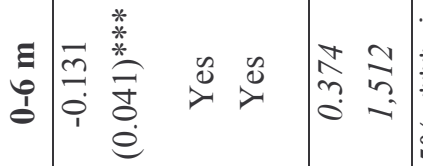

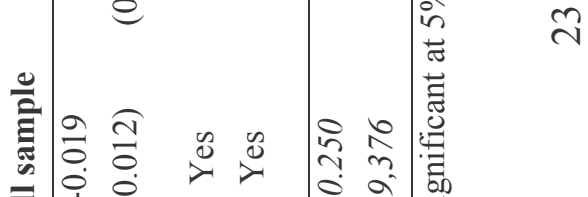

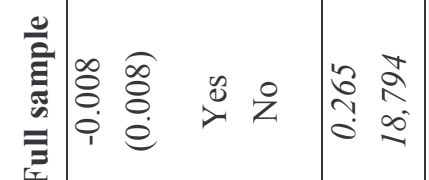

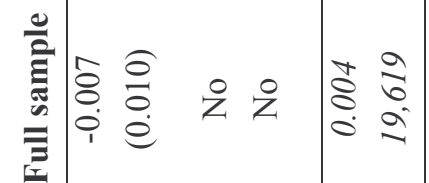

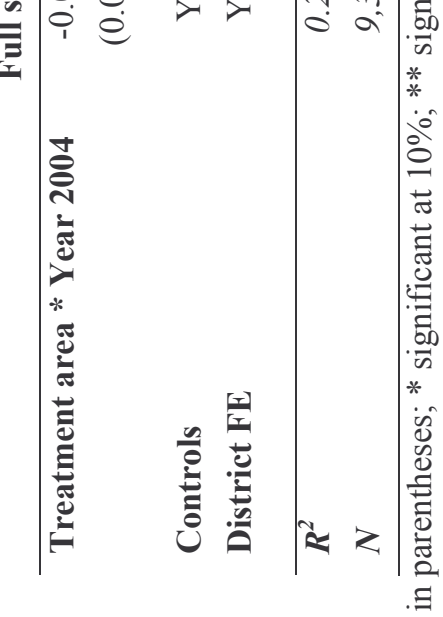

:

뮴

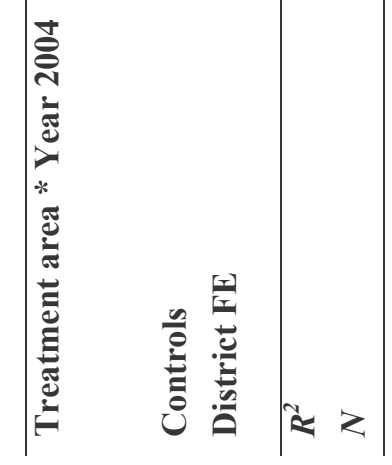




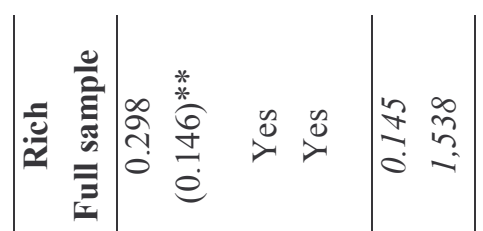

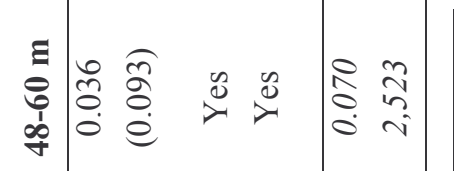

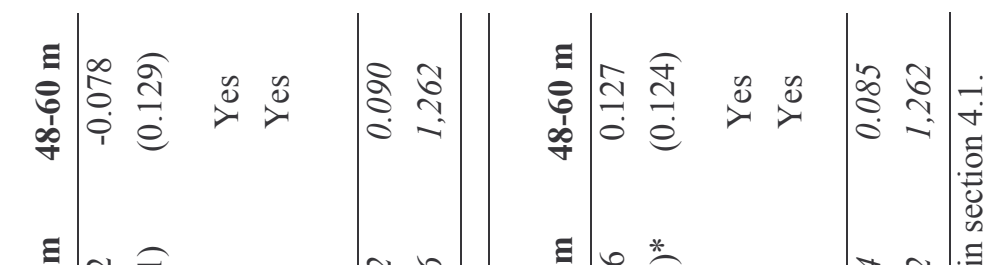

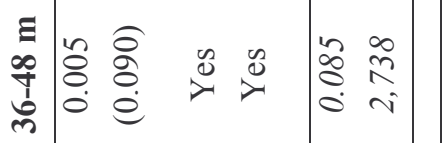

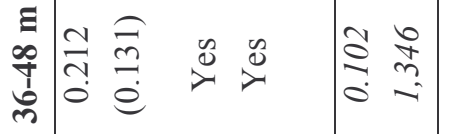

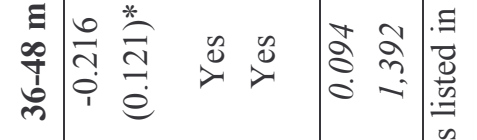

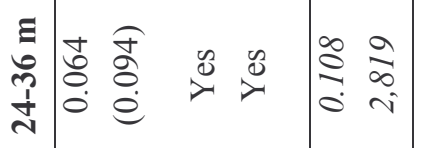

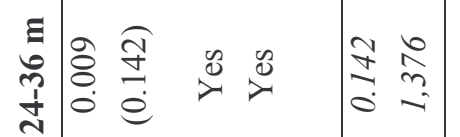

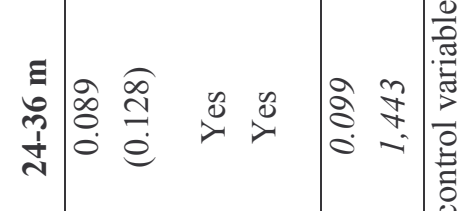

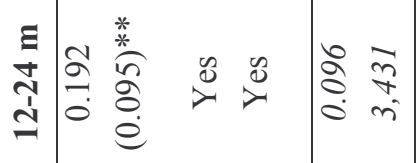

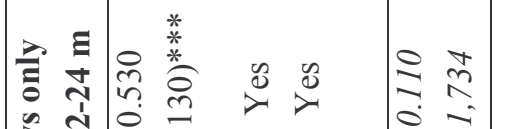

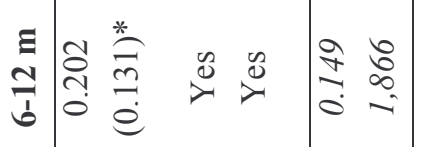

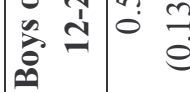

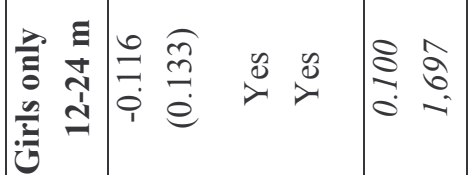

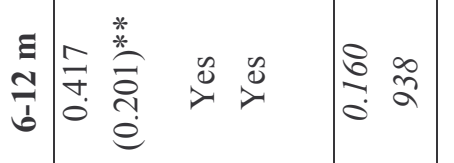

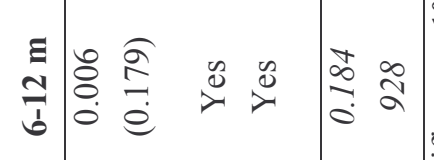

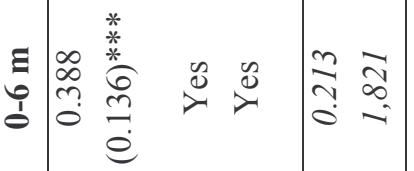

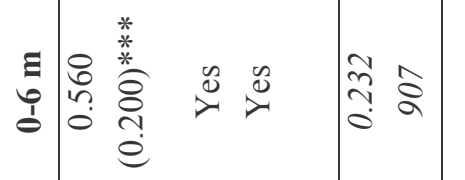

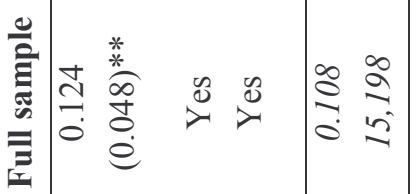

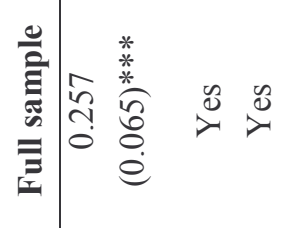

$\therefore$

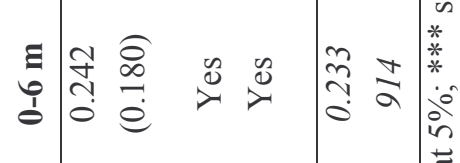

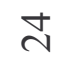

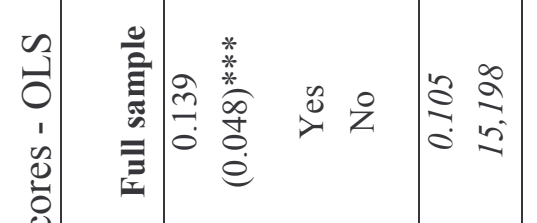
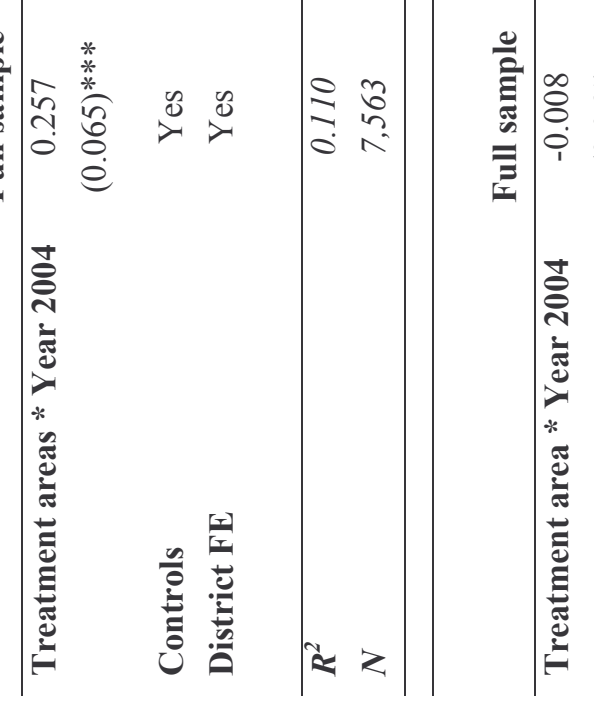

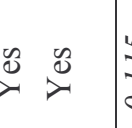

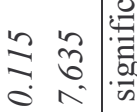

.

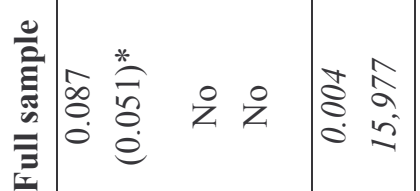

$\approx z$

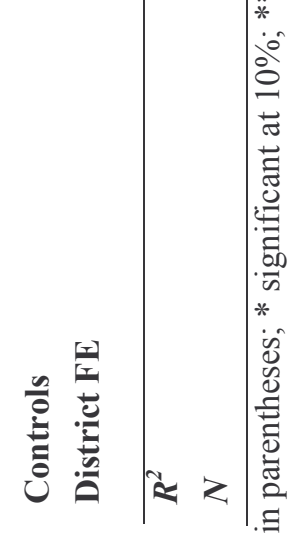




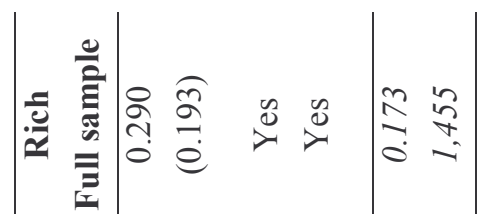

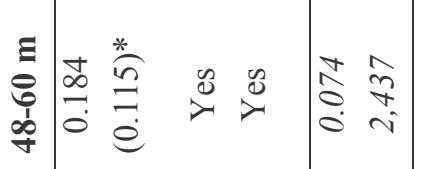

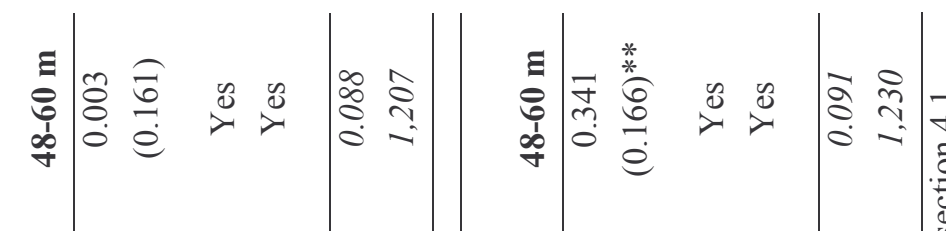

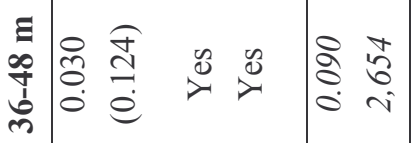

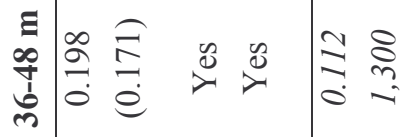

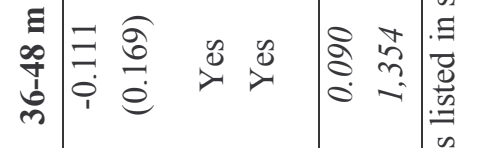

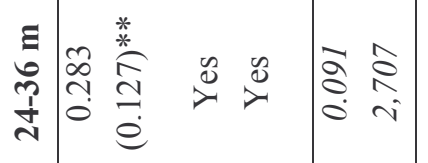

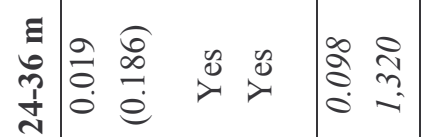

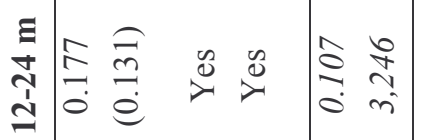

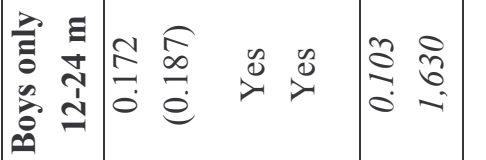

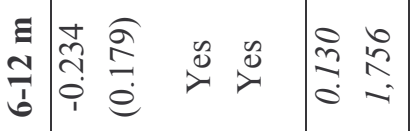

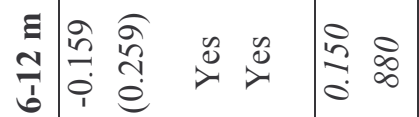

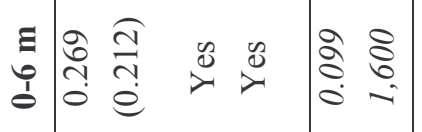

छ

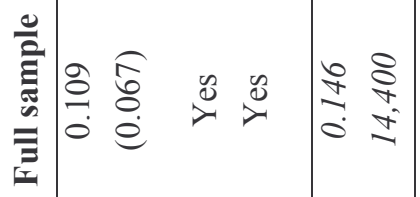

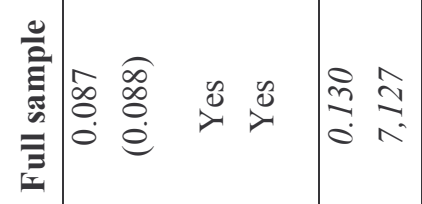

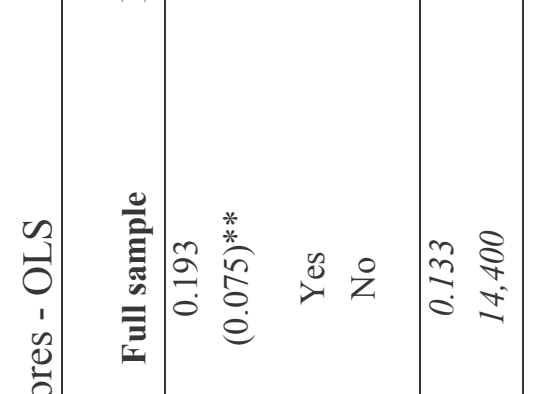

离

N

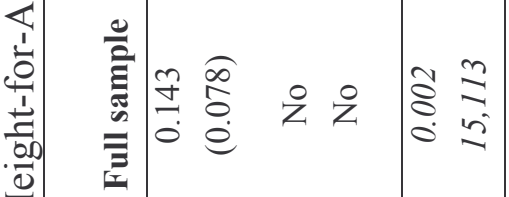

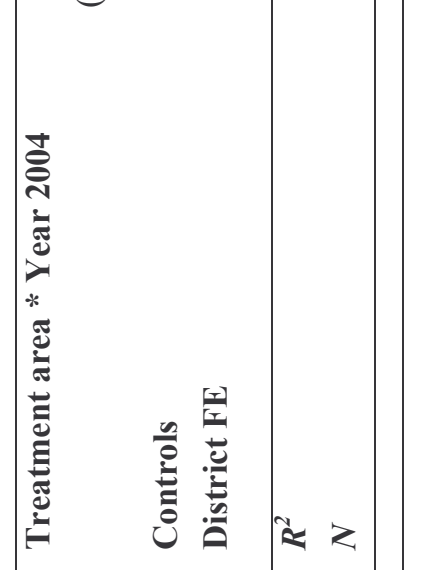

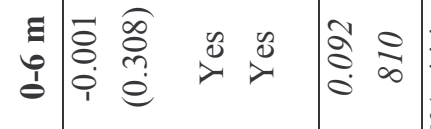

i

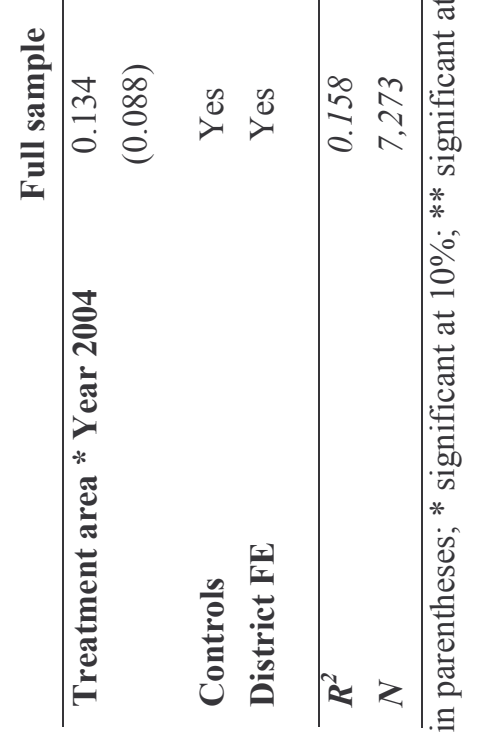




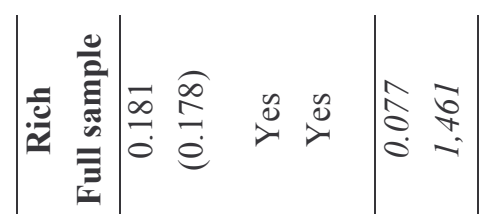

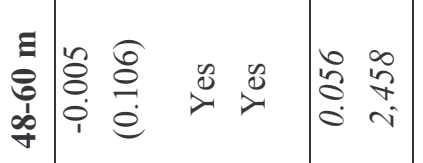

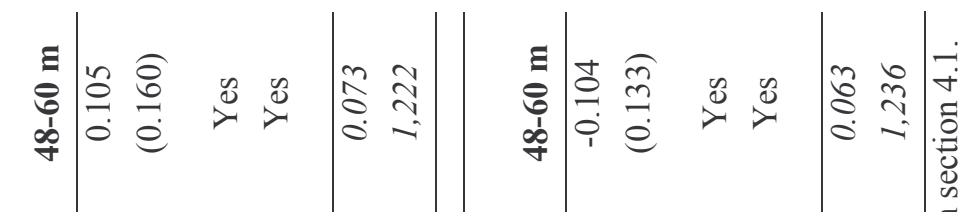

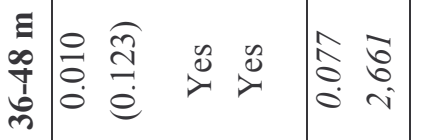

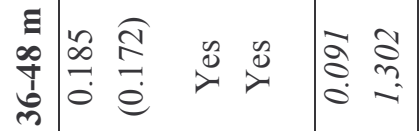

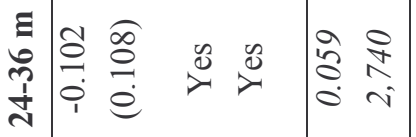

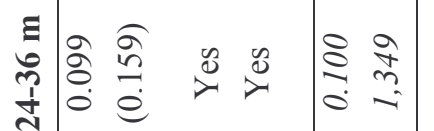

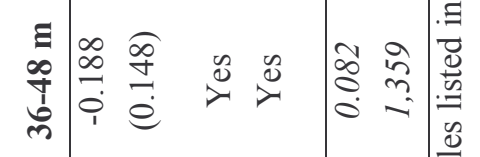

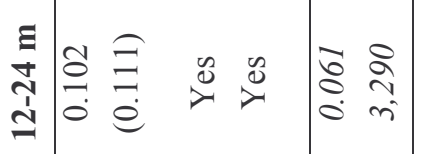

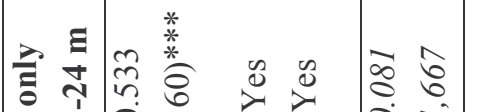

西

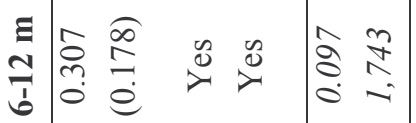

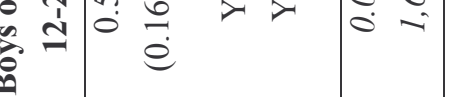

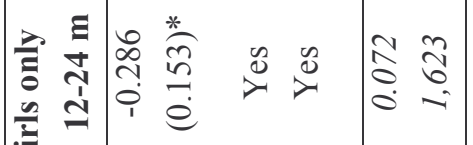

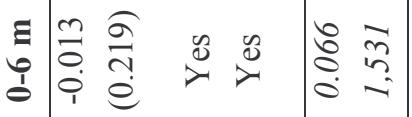

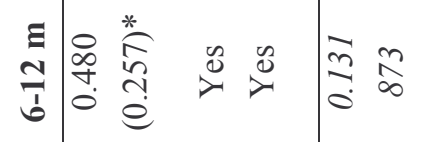

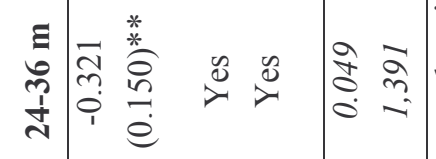

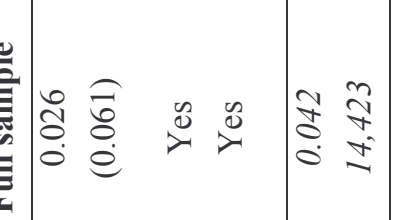

인

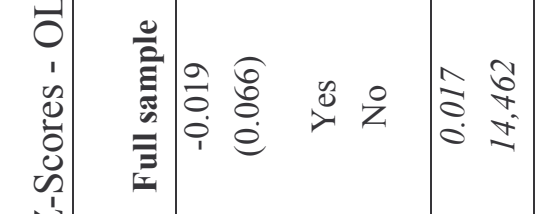

引

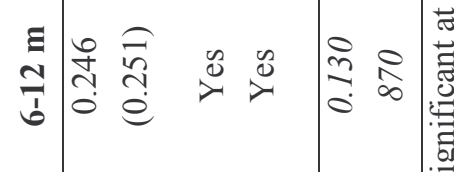

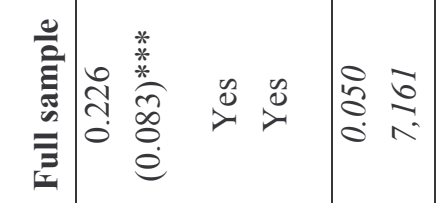
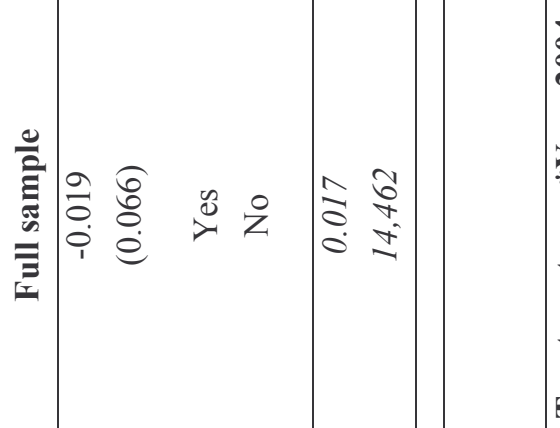

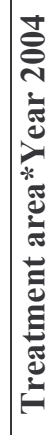

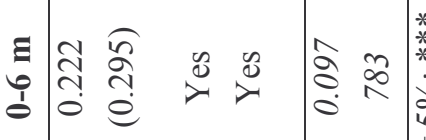

i

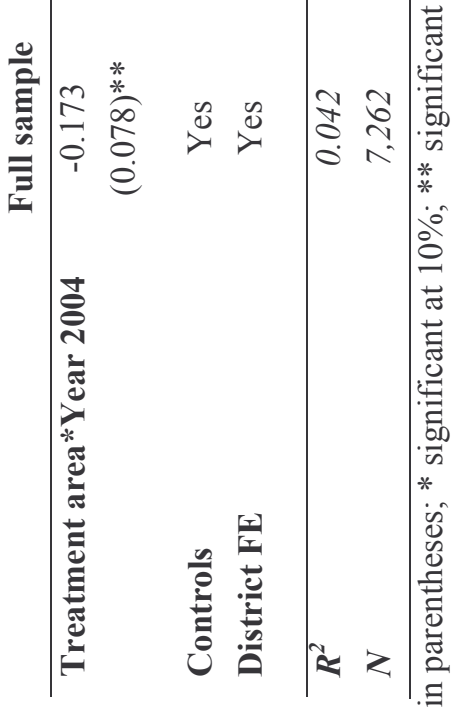

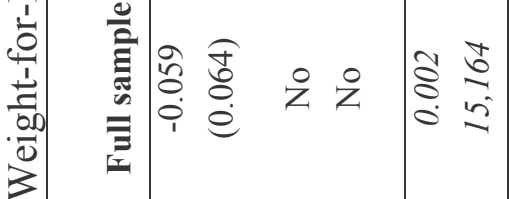

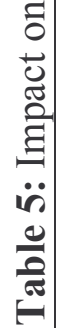

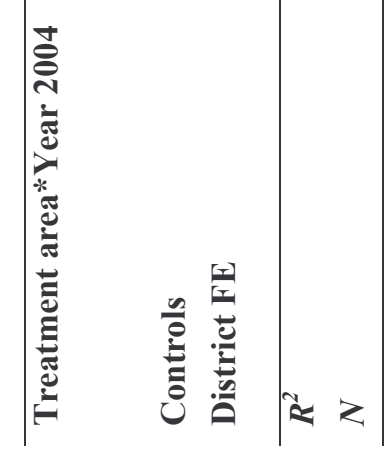




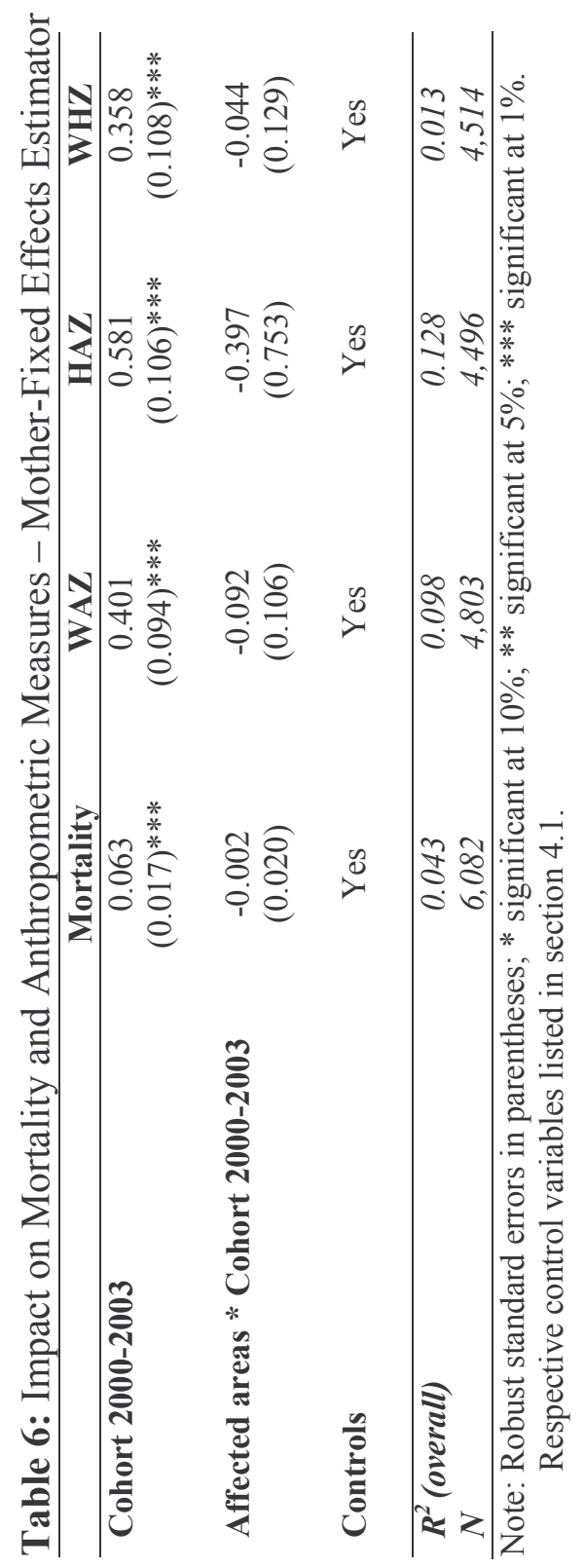




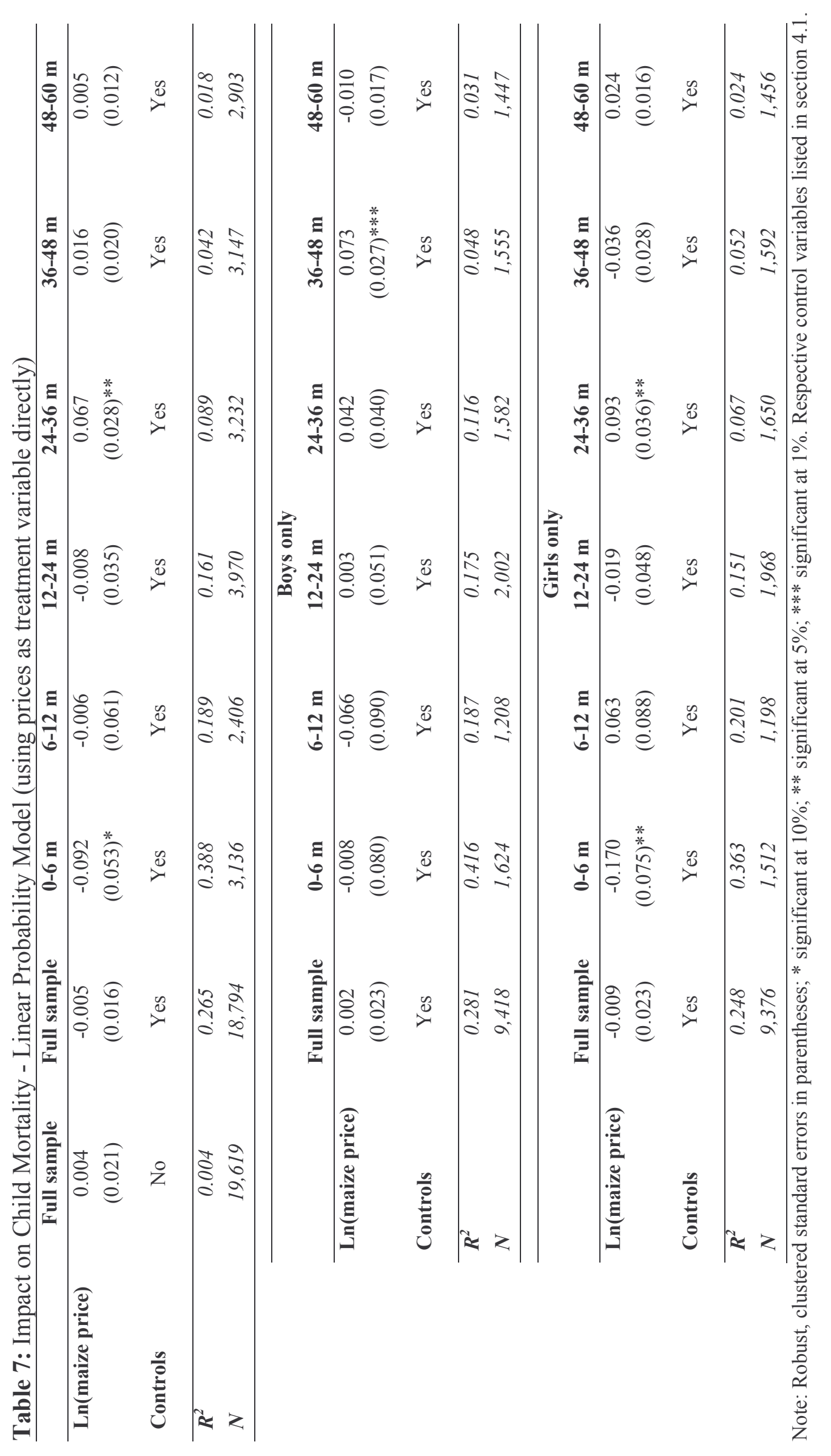




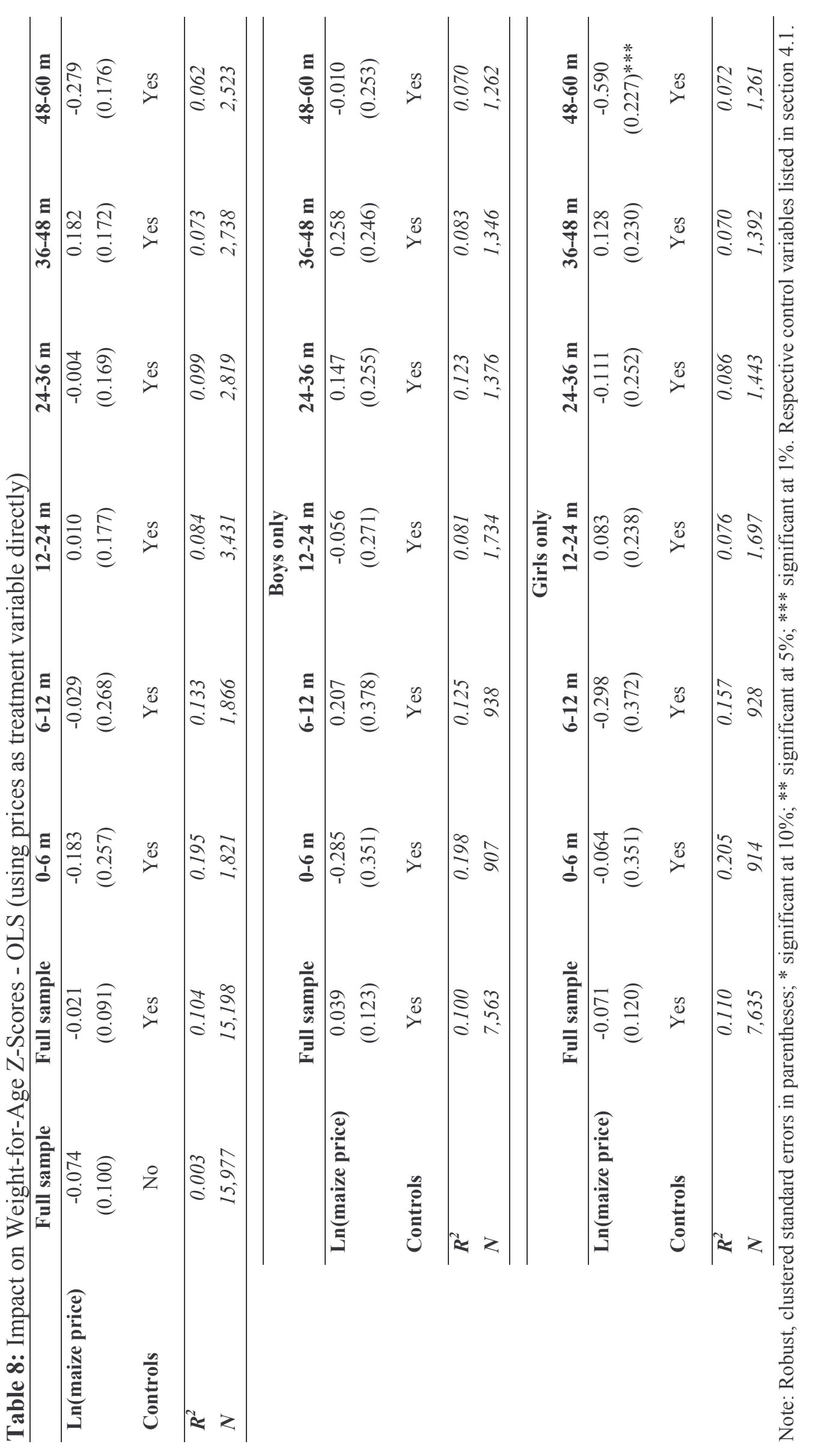

กิ 


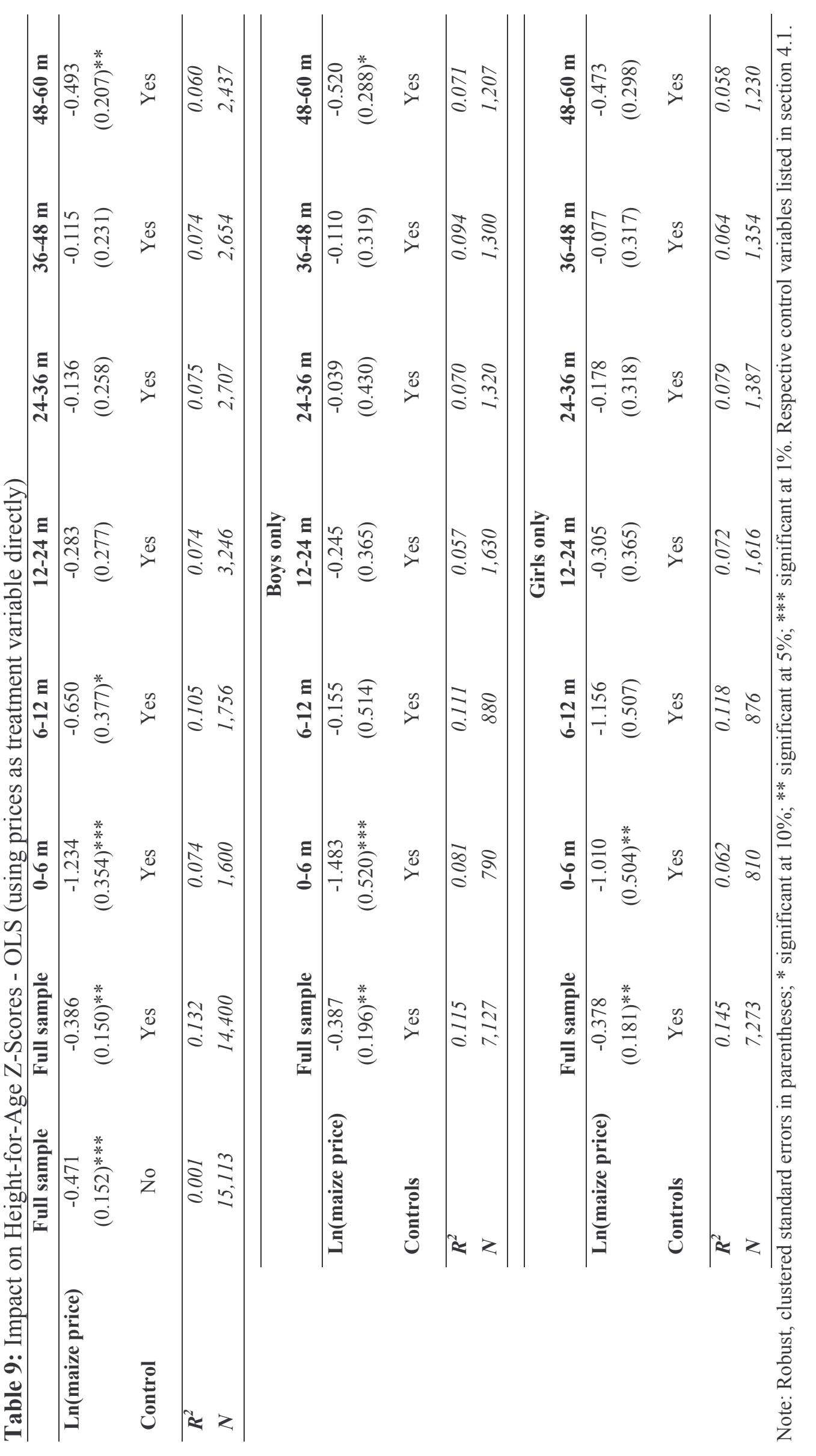




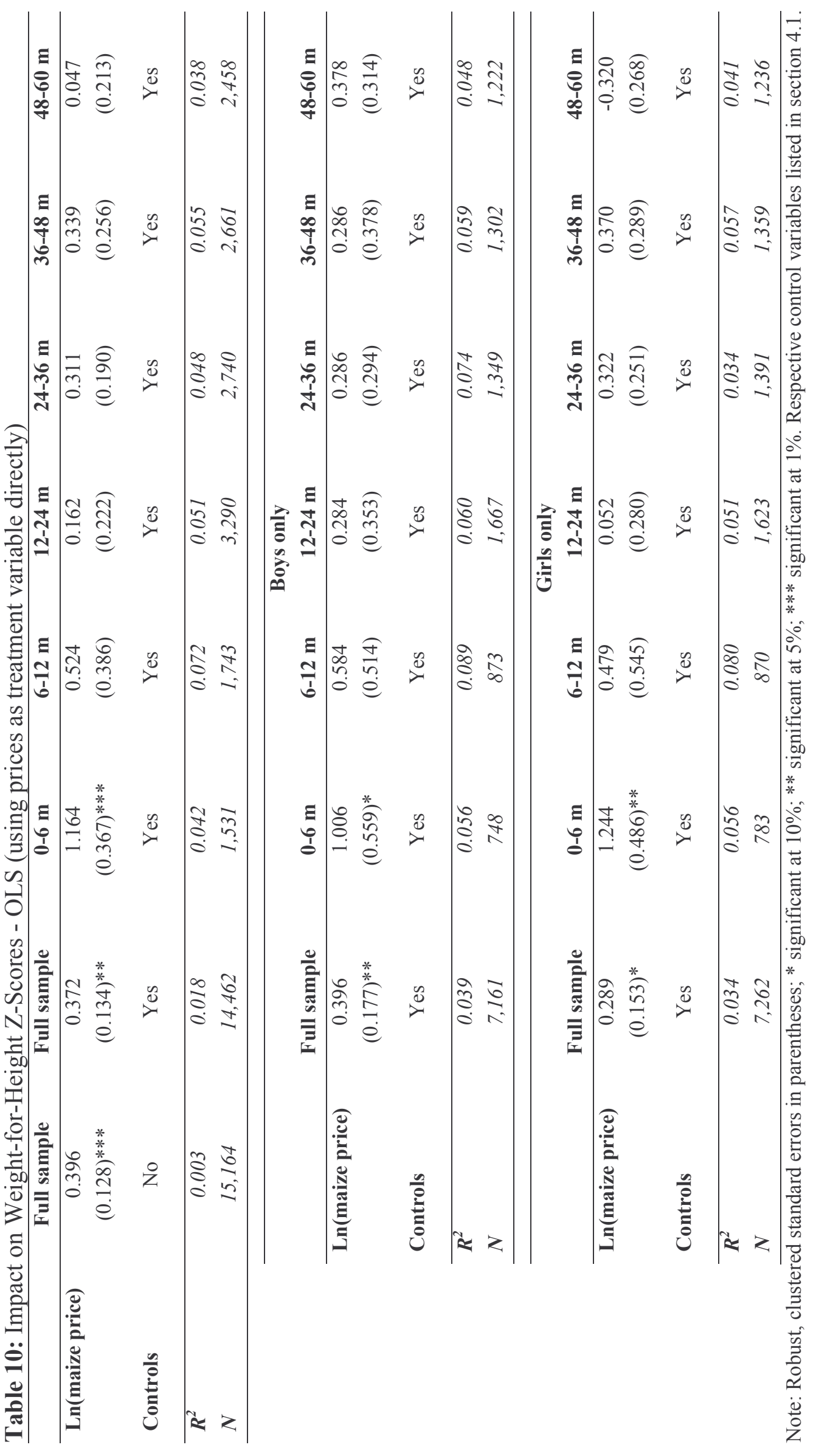


Table 11: Impact assessment of food aid - IV Regressions (using district-specific maize prices as instrument)

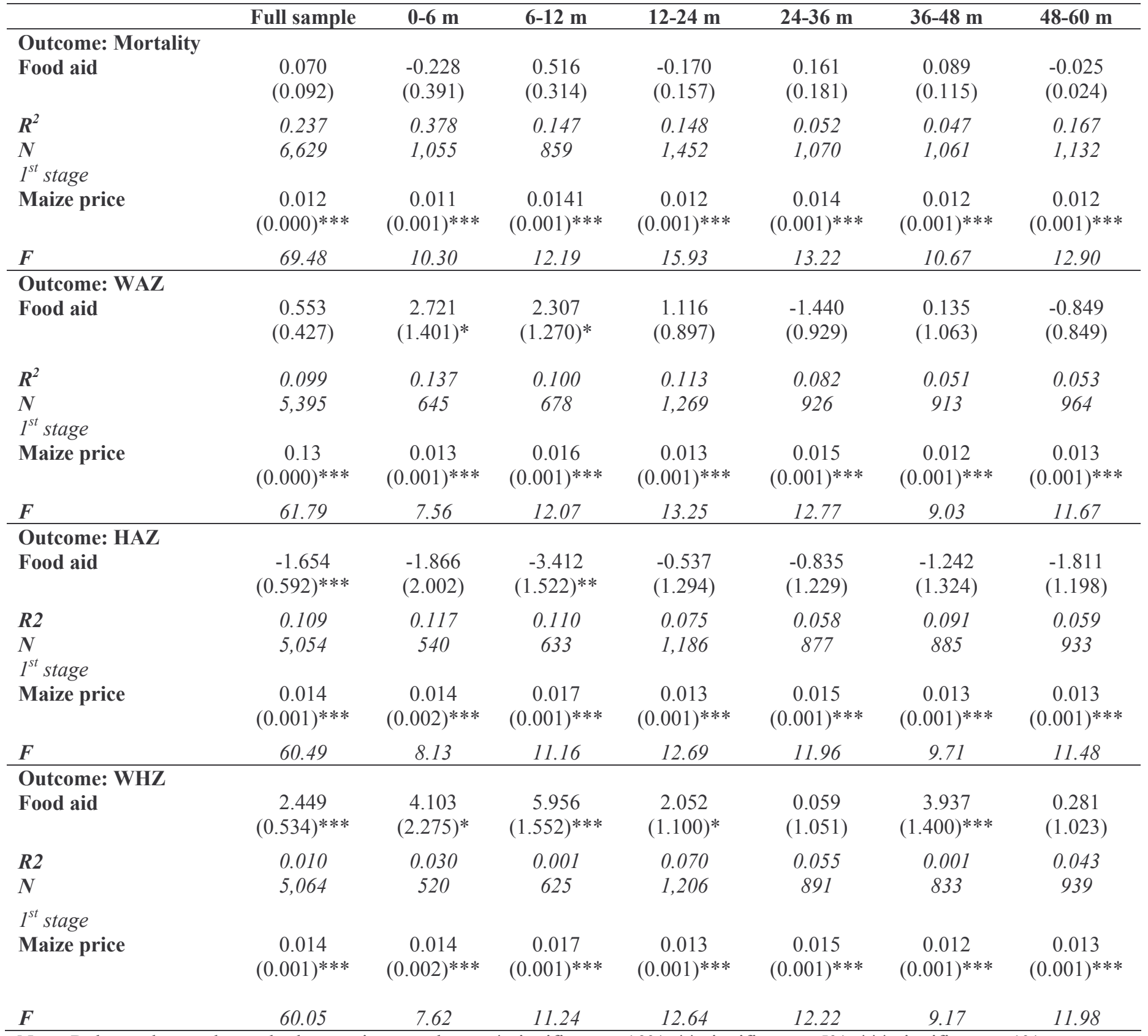

Note: Robust, clustered standard errors in parentheses; * significant at 10\%; ** significant at 5\%; *** significant at $1 \%$. Control variables are the same than those listed in section 4.1 . 
Table A1: Descriptive Statistics

\begin{tabular}{|c|c|c|c|c|c|c|}
\hline Variable & $\begin{array}{l}\text { Affected } \\
\text { Mean } \\
\text { (SD) }\end{array}$ & $\begin{array}{c}2000 \\
\text { Non-affected } \\
\text { Mean } \\
\text { (SD) } \\
\end{array}$ & p-value & $\begin{array}{l}\text { Affected } \\
\text { Mean } \\
\text { (SD) }\end{array}$ & $\begin{array}{c}2004 \\
\text { Non-affected } \\
\text { Mean } \\
\text { (SD) } \\
\end{array}$ & p-value* \\
\hline \multirow[t]{2}{*}{ Dummy child died } & 0.145 & 0.1299 & 0.032 & 0.1033 & 0.0949 & 0.185 \\
\hline & $(0.3522)$ & $(0.3362)$ & & $(0.3043)$ & $(0.2931)$ & \\
\hline \multirow[t]{2}{*}{ Height-for-age SD } & -2.116 & -1.9213 & 0.000 & -2.0064 & -1.9545 & 0.223 \\
\hline & $(1.7767)$ & $(1.7447)$ & & $(1.7813)$ & $(1.7942)$ & \\
\hline \multirow{2}{*}{ Weight-for-age SD } & -1.1402 & -1.0246 & 0.001 & -0.9596 & -0.9313 & 0.349 \\
\hline & (1.3394) & $(1.2768)$ & & $(1.3063)$ & $(1.2899)$ & \\
\hline \multirow[t]{2}{*}{ Weight-for-height SD } & 0.2381 & 0.1882 & 0.151 & 0.3473 & 0.3567 & 0.801 \\
\hline & $(1.5182)$ & $(1.4701)$ & & $(1.5614)$ & $(1.5437)$ & \\
\hline \multirow[t]{2}{*}{ Dummy child is a twin } & 0.041 & 0.0445 & 0.400 & 0.0312 & 0.0386 & 0.051 \\
\hline & $(0.1984)$ & $(0.2063)$ & & $(0.1738)$ & $(0.1926)$ & \\
\hline \multirow[t]{2}{*}{ Dummy child is male } & 0.4996 & 0.4925 & 0.488 & 0.5106 & 0.5032 & 0.484 \\
\hline & $(0.5)$ & $(0.5)$ & & $(0.4999)$ & $(0.5001)$ & \\
\hline \multirow{2}{*}{ Breast fed (months) } & 15.0704 & 15.4507 & 0.043 & 15.4216 & 16.1459 & 0.000 \\
\hline & $(9.1914)$ & $(9.1508)$ & & $(9.2504)$ & $(9.4437)$ & \\
\hline \multirow[t]{2}{*}{ Dummy very small size at birth } & 0.0443 & 0.0453 & 0.823 & 0.0352 & 0.0442 & 0.025 \\
\hline & $(0.2058)$ & $(0.2079)$ & & $(0.1842)$ & $(0.2056)$ & \\
\hline \multirow[t]{2}{*}{ Dummy small size at birth } & 0.1309 & 0.1192 & 0.086 & 0.1242 & 0.1191 & 0.465 \\
\hline & $(0.3373)$ & $(0.3241)$ & & $(0.3298)$ & $(0.324)$ & \\
\hline \multirow[t]{2}{*}{ Dummy average size at birth } & 0.5379 & 0.628 & 0.000 & 0.5002 & 0.4402 & 0.000 \\
\hline & $(0.4986)$ & $(0.4834)$ & & $(0.5)$ & $(0.4965)$ & \\
\hline \multirow{2}{*}{ Dummy large size at birth } & 0.1707 & 0.1457 & 0.001 & 0.2229 & 0.2585 & 0.000 \\
\hline & $(0.3763)$ & $(0.3528)$ & & $(0.4162)$ & $(0.4379)$ & \\
\hline \multirow[t]{2}{*}{ Dummy very large size at birth } & 0.1111 & 0.0539 & 0.000 & 0.0816 & 0.1191 & 0.000 \\
\hline & $(0.3142)$ & $(0.2259)$ & & $(0.2738)$ & $(0.324)$ & \\
\hline \multirow[t]{2}{*}{ Mother's education (years) } & 2.6629 & 3.9159 & 0.000 & 3.3829 & 4.3244 & 0.000 \\
\hline & $(2.8842)$ & $(3.1983)$ & & $(3.2814)$ & $(3.3321)$ & \\
\hline \multirow[t]{2}{*}{ Mother married } & 0.845 & 0.8936 & 0.000 & 0.7902 & 0.8671 & 0.000 \\
\hline & $(0.362)$ & $(0.3083)$ & & $(0.4072)$ & $(0.3395)$ & \\
\hline \multirow{2}{*}{ Mother's age at birth } & 26.049 & 25.8986 & 0.296 & 25.8524 & 26.0541 & 0.159 \\
\hline & $(7.1717)$ & $(6.8199)$ & & $(6.8334)$ & $(6.7773)$ & \\
\hline \multirow[t]{2}{*}{ Mother's height-for-age SD } & -1.3834 & -1.329 & 0.007 & -1.3623 & -1.3049 & 0.008 \\
\hline & $(0.9653)$ & $(0.9995)$ & & $(1.0021)$ & $(1.0089)$ & \\
\hline \multirow[t]{2}{*}{ Mother's weight-for-age SD } & -0.7516 & -0.671 & 0.000 & -0.7288 & -0.6888 & 0.027 \\
\hline & $(0.7867)$ & $(0.8232)$ & & $(0.8315)$ & $(0.8672)$ & \\
\hline Mother's BMI & 21.8669 & 22.0639 & 0.001 & 21.8523 & 21.9978 & 0.017 \\
\hline & $(2.7881)$ & $(2.7221)$ & & $(2.7802)$ & $(2.9246)$ & \\
\hline Dummy agricultural HH & 0.5618 & 0.591 & 0.004 & 0.6044 & 0.6923 & 0.000 \\
\hline & $(0.4962)$ & $(0.4917)$ & & $(0.489)$ & $(0.4616)$ & \\
\hline Dummy poor $\mathrm{HH}$ (40 ${ }^{\text {th }}$ percentile) & 0.4637 & 0.4749 & 0.274 & 0.4974 & 0.394 & 0.000 \\
\hline & $(0.4987)$ & $(0.4994)$ & & $(0.5)$ & $(0.4887)$ & \\
\hline Dummy medium HH (40th percentile) & 0.4365 & 0.3923 & 0.000 & 0.4269 & 0.5015 & 0.000 \\
\hline & $(0.496)$ & $(0.4883)$ & & $(0.4947)$ & $(0.5001)$ & \\
\hline Dummy rich $\mathrm{HH}\left(40^{\text {th }}\right.$ percentile $)$ & 0.0998 & 0.1328 & 0.000 & 0.0757 & 0.1045 & 0.000 \\
\hline & $(0.2998)$ & $(0.3394)$ & & $(0.2645)$ & $(0.3059)$ & \\
\hline Dummy female headed $\mathrm{HH}$ & 0.2437 & 0.1932 & 0.000 & 0.2154 & 0.1504 & 0.000 \\
\hline & $(0.4293)$ & $(0.3948)$ & & $(0.4111)$ & $(0.3575)$ & \\
\hline No. of HH members & 5.4501 & 5.7428 & 0.000 & 5.3625 & 5.7209 & 0.000 \\
\hline & $(2.5231)$ & $(2.4366)$ & & $(2.1231)$ & $(2.261)$ & \\
\hline No. of children under 5 & 1.6617 & 1.7007 & 0.029 & 1.7146 & 1.7333 & 0.281 \\
\hline & $(0.868)$ & $(0.8726)$ & & $(0.7956)$ & $(0.878)$ & \\
\hline$N$ & 5,799 & 4,043 & & 6,226 & 3,551 & \\
\hline
\end{tabular}

Note: * The p-value reported gives an indication of a potential equality of means (null hypothesis). 
Table A2: Impacts on Mortality and Anthropometry - 'Placebo' Test using 1992 and 2000 DHS Data

\begin{tabular}{lcccc}
\hline & $\begin{array}{c}\text { Mortality } \\
\text { Full sample }\end{array}$ & $\begin{array}{c}\text { WAZ } \\
\text { Full sample }\end{array}$ & $\begin{array}{c}\text { HAZ } \\
\text { Full sample }\end{array}$ & $\begin{array}{c}\text { WHZ } \\
\text { Full sample }\end{array}$ \\
\hline Treatment area * Year 2000 & 0.014 & -0.024 & -0.130 & 0.105 \\
& $(0.014)$ & $(0.079)$ & $(0.085)$ & $(0.096)$ \\
Controls & Yes & Yes & Yes & Yes \\
District FE & Yes & Yes & Yes & 0.157 \\
\hline $\boldsymbol{R}^{2}$ & 0.250 & 0.090 & 10,015 & 10,048 \\
$\boldsymbol{N}$ & 13,059 & 10,353 & & 0.035 \\
\hline
\end{tabular}

Note: Robust, clustered standard errors in parentheses; $*$ significant at 10\%; ** significant at 5\%; *** significant at $1 \%$. Respective control variables listed in section 4.1. 
Figure 1: Maize Production in Malawi (1986-2006)

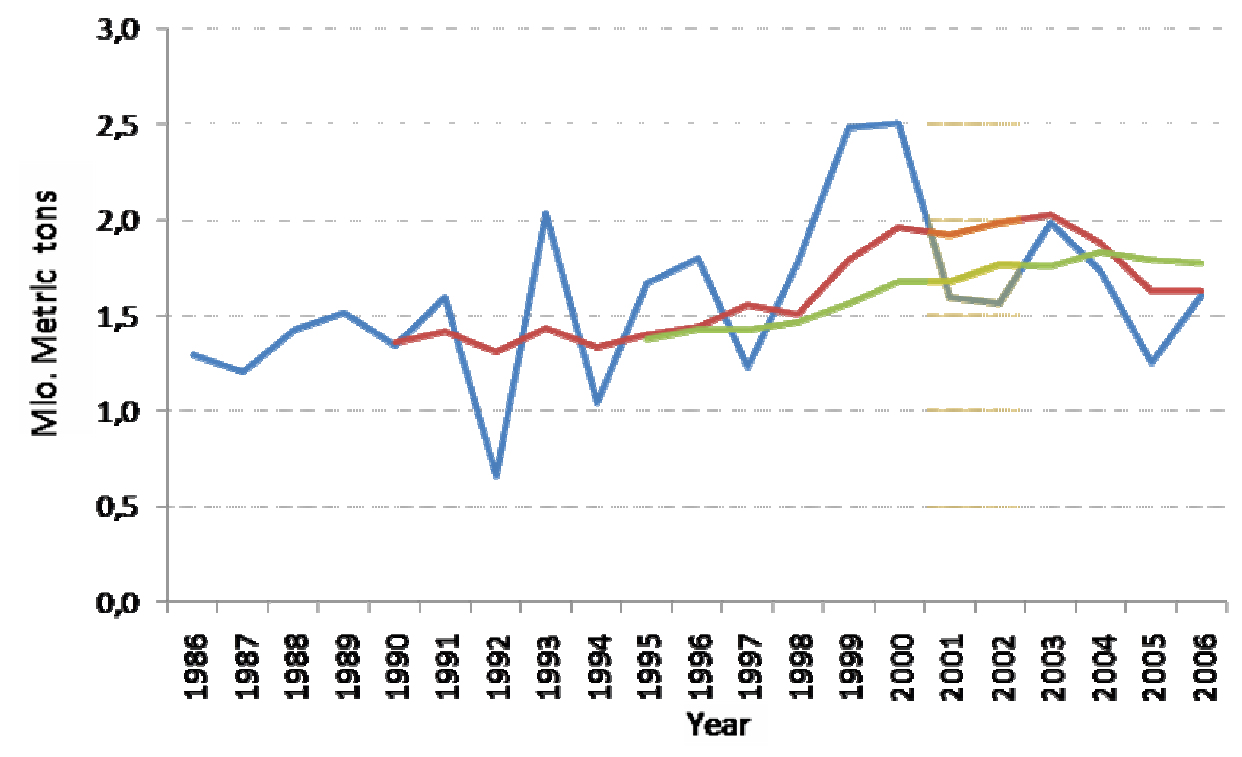

Maize production $\quad 5$ years moving average $\quad 10$ years moving average

Source: Data from FAO Statistics Division (2008)

Figure 2: Real National Average Maize Market Price 1990 - 2007 and Monthly Average Prices during the Crisis
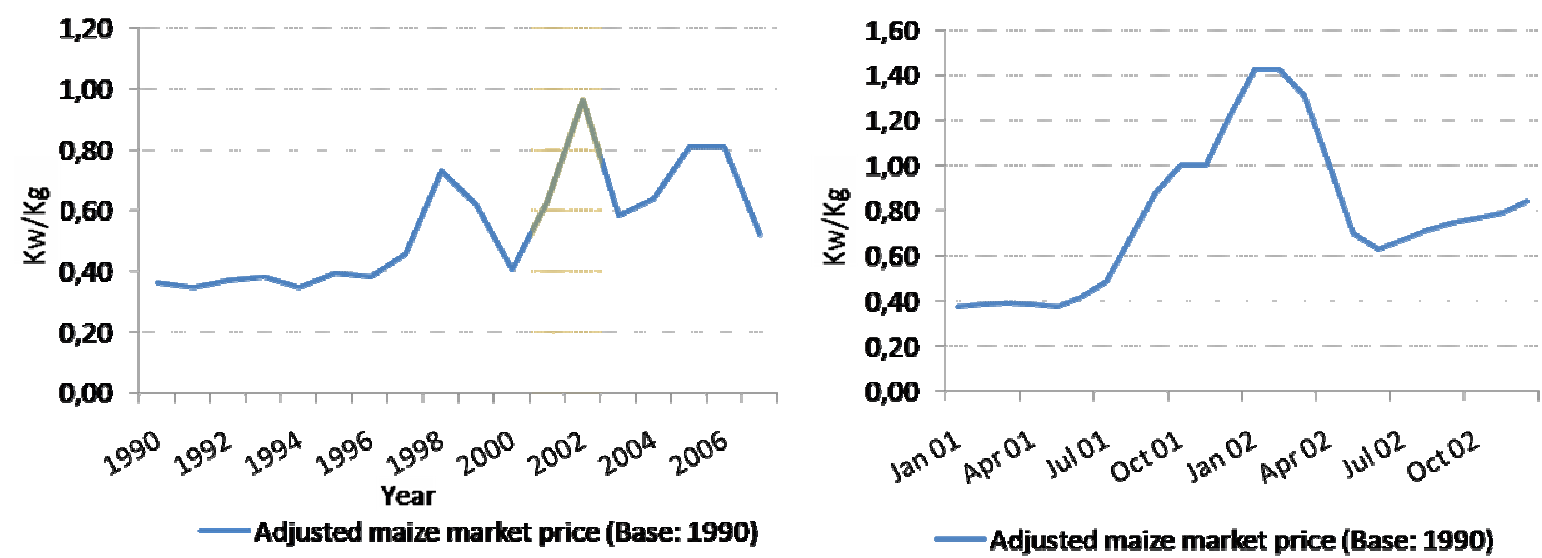

Source: Data from FEWSNET and NSO (2008) 
Figure 3: Monthly Maize Market Prices from Selected Markets across the Country

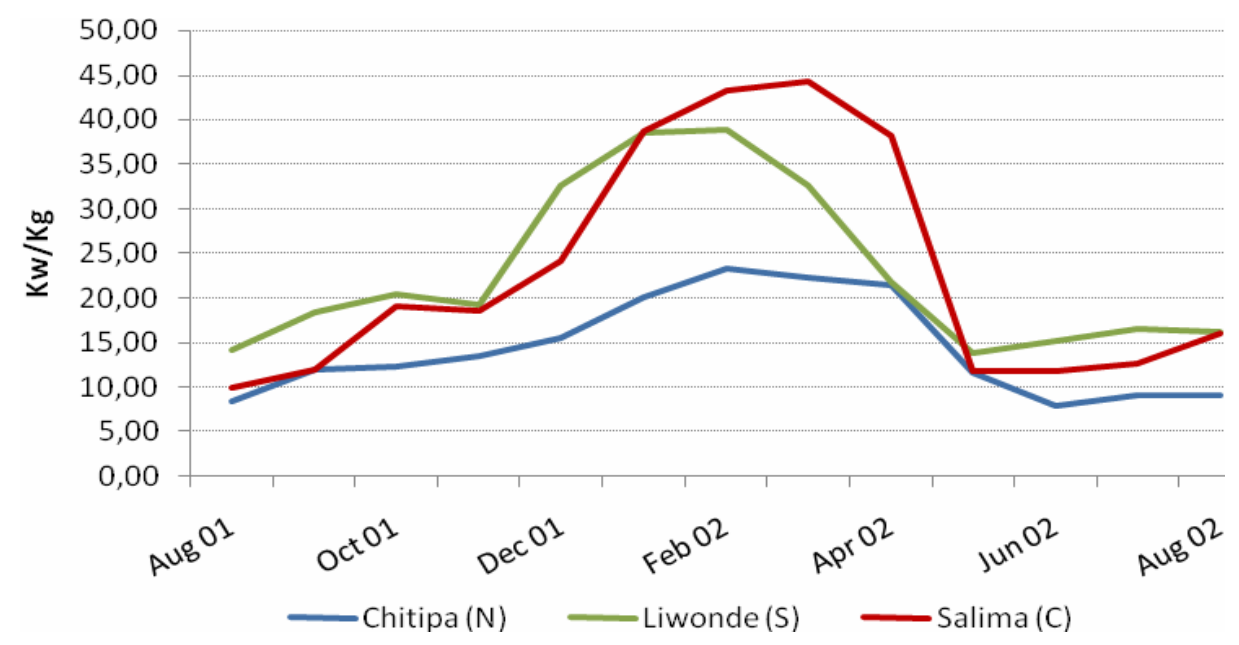

Source: Data from FEWSNET (unpublished)

Figure 4: Average Maize Market Prices (1993-2007)

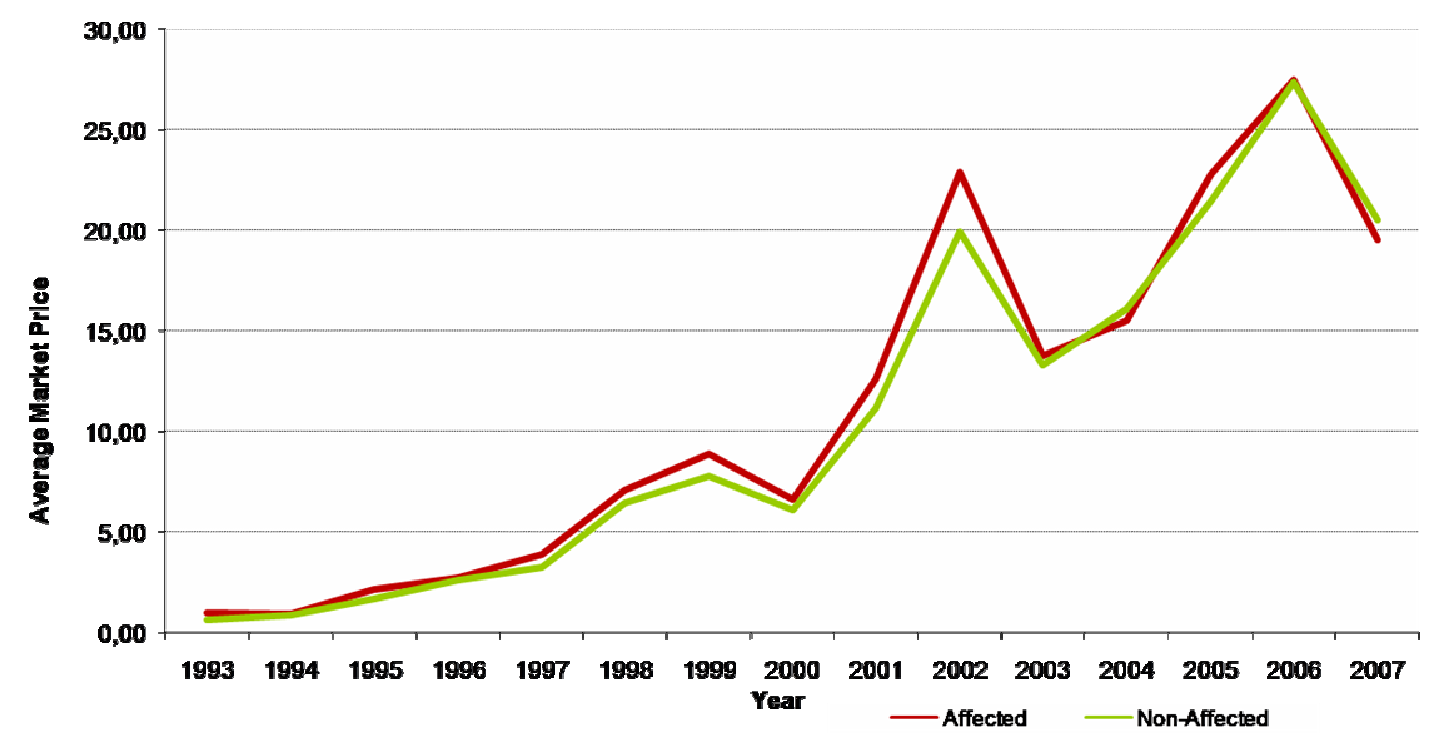

Source: Data from FEWSNET (unpublished) 